Manuscript in preparation for Marine Chemistry

\title{
Assessment of the stability, sorption, and exchangeability of marine dissolved and colloidal metals
}

\author{
L.T. Jensen ${ }^{1}$, N.J.Wyatt ${ }^{2,3}$, W.M. Landing ${ }^{3}$, J.N. Fitzsimmons ${ }^{1}$
}

' Department of Oceanography, Texas A\&M University, College Station, TX 77843, USA.

${ }^{2}$ School of Ocean and Earth Sciences, National Oceanography Centre, University of

Southampton, Southampton, SO14 3ZH, UK.

${ }^{3}$ Department of Earth, Ocean and Atmospheric Science, Florida State University, Tallahassee, FL 32306, USA.

\begin{abstract}
The size partitioning of dissolved trace metals is an important factor for determining reactivity and bioavailability of metals in marine environments. This, alongside the advent of more routine shipboard ultrafiltration procedures, has led to increased attention in determining the colloidal phase of metals such as Fe in seawater. While clean and efficient filtration, prompt acidification, and proper storage have long been tenets of trace metal biogeochemistry, few studies aim to quantify the kinetics of colloidal exchange and metal adsorption to bottle walls during storage and acidification. This study evaluates the effect of storage conditions on colloidal size partitioning, the kinetics of colloid exchange over time, and the timescale of bottle wall adsorption and desorption for dissolved $\mathrm{Fe}, \mathrm{Cu}, \mathrm{Ni}, \mathrm{Zn}, \mathrm{Cd}, \mathrm{Pb}, \mathrm{Mn}$ and $\mathrm{Co}$. We report that preservation of dissolved size partitioning is possible only for $\mathrm{Fe}$ and only under frozen conditions. All metals except Mn and Cd show regeneration of the colloidal phase following its removal in as short as 14 hours, validating the importance of prompt ultrafiltration. Adsorption of metals to bottle walls is a well-known sampling artifact often cited for $\mathrm{Fe}$ and assumed to be potentially significant for other metals as well. However, only Fe and Co showed significant proclivity to adsorption onto low density polyethylene bottle walls, sorbing a maximum of 91 and $72 \%$ over 40 months, respectively. After 20 weeks of acidification neither Fe nor Co desorbed to their original concentrations, leading to an acidified storage recommendation of 30 weeks prior to analyses following storage of unacidified samples for long periods of time. This study provides empirical recommendations for colloidal and dissolved trace metal methodology while also paving the way for much-needed future methods testing.
\end{abstract}


Colloids represent a dynamic class of compounds that exert control on the fate (transport, reactivity, and bioavailability) of trace metals in seawater. A colloid is distinguished from a truly dissolved species (here called "soluble" species) based on its size, where the transition from soluble to colloidal compounds theoretically occurs when the internal characteristics of a compound become significantly differentiated from the solution such that an interface is established [Wells, 2002]. This surficial interface is critical for the adsorption of trace metals,

42 and given the larger relative surface area of colloids compared to their particulate analogs,

43 colloids can serve as an important adsorptive sink for metals from the dissolved phase.

44 Moreover, given the physical inclination of colloids to aggregate [Honeyman and Santschi,

45 1988], adsorption followed by colloidal aggregation can serve as an important output vector of

46 metals from the ocean when they ultimately sink as particles to the sediments. Thus, colloids

47 play an important role in marine biogeochemistry as an intermediary in the continuum of size

48 fractions in seawater and, as aggregators, as a part of the "scavenging" removal of elements from 49 the ocean.

Additionally, the reactivity and bioavailability of trace metals in the ocean is closely tied to their physicochemical speciation. For iron $(\mathrm{Fe})$, which is the best studied of the micronutrient metals, species in the smallest soluble size fraction (typically $<3 \mathrm{~nm}$ ) have been established as

53 the most bioavailable to marine phytoplankton, although larger Fe colloids (3-200 nm) are also

54 thought to be bioavailable, depending on their chemical composition [Chen and Wang, 2001;

55 Chen et al., 2003; Hassler et al., 2011]. The colloidal distributions of other metals have been investigated in some earlier studies but remain poorly constrained in open ocean regions, with significant variability dependent on ultrafiltration method used and region studied [Buesseler et al., 1996; Wen et al., 1999; Doucet et al., 2007]. However, it remains clear that the size and chemical composition of colloids play important roles in the bioavailability and reactivity of dissolved trace metals in seawater.

Over the last few decades, several isolation methods have been applied to the sampling of marine colloids: solid-phase extraction [Louchouarn et al., 2000], flow field-flow fractionation (FFFF) [Stolpe et al., 2010; Baalousha et al., 2011], chromatography [Minor et al., 2002], gel

64 filtration and stirred-cell ultrafiltration [Guo and Santschi, 2007], as well as more recent methods 65 such as Vivaspin centrifuge ultrafilters [Schlosser et al., 2013]. However, ultrafiltration methods such as Anopore filtration ( $0.02 \mu \mathrm{m}$ pore size cutoff) and the widely used cross flow filtration (1-

$671000 \mathrm{kDa}$ ) are now among the more common methods for metal colloid studies as they allow

68 large quantities of water to be filtered at once over a large range of sizes [Buesseler et al., 1996;

69 Guo and Santschi, 2007; Fitzsimmons and Boyle, 2014b]. These have led to a multitude of 70 global ocean investigations of the size partitioning of dissolved Fe (synthesized in [Fitzsimmons 
71 and Boyle, 2014a; von der Heyden and Roychoudhury, 2015]), which have shown that the size

72 partitioning varies spatially and is critically dependent on which pore size cutoff is used, since

73 the size distribution of Fe colloids is itself dynamic [Stolpe et al., 2010; Baalousha et al., 2011].

74 Unfortunately, few studies have compared colloidal metal concentrations across a range of

75 ultrafiltration pore sizes in seawater at the same sites [Larsson et al., 2002; Ingri et al., 2004;

76 Fitzsimmons and Boyle, 2014a], likely because of the time consuming nature of ultrafiltration

77 itself. This would help reveal the true size distribution of marine colloidal metals.

78 As is true for any operationally-defined method, it is important to rigorously calibrate the

79 method and test for potential artifacts so that different users can expect to acquire the same

80 results. For colloid ultrafiltration methods, methodological artifacts can arise after initial

81 particulate removal via bulk filtration $(>0.2 \mu \mathrm{m}$ pore size), which is required since particles can

82 clog ultrafilters and/or serve as sorptive surfaces, both before and during the slow ultrafiltration

83 process. Some of these artifacts were reviewed during an intercomparison exercise early in the

84 development of colloidal methods [Buesseler et al., 1996] as well as during later studies [Chen et

85 al., 2004; Schlosser et al., 2013; Fitzsimmons and Boyle, 2014b]. For metals, the most

86 significant concerns addressed were contamination and recovery differences across ultrafilters

87 [Reitmeyer et al., 1996]. While a subset of these ultrafilters have been vetted and are in regular

88 use today [Larsson et al., 2002; Fitzsimmons and Boyle, 2014a; Fitzsimmons et al., 2015b],

89 potential artifacts still exist and warrant further constraint, including the underexplored kinetics

90 of colloidal exchange with other solution components and/or with bottle walls, which are

91 especially critical when it can take tens of minutes to many hours to ultrafilter a single seawater

92 sample.

93 Previous studies have demonstrated that sorption and desorption from colloidal

94 complexes is highly dependent on $\mathrm{pH}$, ionic strength of the solution, temperature, and

95 particularly the composition of particles, leading to exchange on the timescale of hours to days

96 [Scheinost et al., 2001; Roberts et al., 2003]. Marine colloids are thought to be primarily organic

97 in nature, comprising a combination of humic-type substances and products of biological activity

98 such as exopolymeric substances [Gaffney et al., 1996; Ron and Rosenberg, 2001] and, more

99 generically, dissolved organic matter (DOM) [Santschi, 2018]. Dissolved organic carbon (DOC)

100 in particular is largely colloidal in size and, as such, is subject to rapid turnover, forming an

101 important part of the global carbon cycle [Baskaran et al., 1992; Benner et al., 1992; Santschi et

102 al., 1995; Guo and Santschi, 1997; Opsahl and Benner, 1997; Wen et al., 1997]. If metals are

103 bound to or otherwise incorporated within these organic colloids, they would be more vulnerable

104 to exchange over short timescales.

105 Sorption of trace metals to sub-sample bottle walls during storage also represents a

106 potential artifact affecting measurements in seawater. The loss of various trace metals to bottle 
107 walls during storage is well documented ([Massee et al., 1981], references therein), leading to the 108 standardization of storage procedures that typically involve acidification of samples prior to 109 analysis [Pellenbarg and Church, 1978; Bruland and Rue, 2001; Lohan et al., 2005].

110 Furthermore, the bottle material and physicochemical speciation of each metal are known to 111 affect the overall bottle wall sorption loss [Starik et al., 1963; James and Healy, 1972a;

112 Pellenbarg and Church, 1978; Fischer et al., 2007]. While previous studies have elucidated losses 113 of dissolved, soluble, and colloidal Fe to bottle wall sorption [Schlosser et al., 2011;

114 Fitzsimmons and Boyle, 2012], no recent rigorous kinetic testing has been performed to examine 115 adsorptive loss of other trace metals to bottle walls. Moreover, trace metals such as manganese $116(\mathrm{Mn})$, cobalt $(\mathrm{Co})$, nickel $(\mathrm{Ni})$, copper $(\mathrm{Cu})$, zinc $(\mathrm{Zn})$, and cadmium $(\mathrm{Cd})$ each have different 117 inorganic speciation in seawater compared with Fe [Byrne, 2002], as well as varying degrees of 118 complexation to ligands [Bruland et al., 2013]. Thus, we might expect that adsorption and 119 subsequent desorption of these metals would be different from Fe and dependent on their 120 speciation at seawater $\mathrm{pH}$, leading to important considerations of the timing of sample 121 acidification and analysis, and for colloids, the slow ultrafiltration process. Naturally, these 122 concerns raise questions of whether seawater samples can be preserved for ultrafiltration back in 123 the lab, when more time and supplies would allow for better streamlining of the ultrafiltration 124 process.

125 Here, we report the results of four experiments designed to answer questions related to 126 the kinetics of colloidal metal exchange and adsorption to bottle walls, as well as the efficacy of 127 preserving the colloidal size partitioning of metal samples: 1) a "Colloid Preservation 128 Experiment" to assess the ability to preserve multi-metal marine colloidal size partitioning under 129 room temperature and frozen conditions over several weeks, 2) a "Colloid Exchangeability 130 Experiment" to assess the timescale of colloid re-formation rates from the soluble phase at room 131 temperature over several days, 3) a "Bottle Adsorption Kinetics Experiment" to assess the 132 timescale of adsorption onto low density polyethylene (LDPE) bottle walls using two different 133 bottle volumes, and 4) a "Bottle Desorption Kinetics Experiment" to assess the timescale of 134 desorption from the same LDPE bottle walls. We analyzed these experimental treatments for 135 their Fe concentrations but also, for the first time, extended our measurements to the size 136 partitioning of $\mathrm{Mn}, \mathrm{Co}, \mathrm{Ni}, \mathrm{Cu}, \mathrm{Zn}, \mathrm{Cd}$, and lead $(\mathrm{Pb})$. The goal of these experiments was to 137 provide recommendations regarding sample storage prior to acidification, constraints on how 138 long samples can be stored before ultrafiltration and the influence of the ultrafiltration processing 139 time itself, in order to avoid artifacts during future field studies.

141 Methods

142 Sample collection 
Water used for these experiments was collected on three research cruises: 1) in

144 September 2015 during the U.S. Arctic GEOTRACES GN01 cruise (Station 52: 77.50 N, $145148.01^{\circ} \mathrm{W}, 100 \mathrm{~m}$ depth) aboard the USCGC Healy for the Bottle Adsorption/Desorption

146 Kinetics Experiments, 2) in January 2016 in the Southern Ocean during the Palmer Long-Term

147 Ecosystem Research (Pal-LTER) cruise aboard the ARSV Laurence Mckinley Gould (Station

$148600.040:-64.93^{\circ} \mathrm{N}, 64.40^{\circ} \mathrm{W}, 1320 \mathrm{~m}$ depth for the Colloid Preservation Experiment; and Station $149200.000:-67.77^{\circ} \mathrm{N},-69.95^{\circ} \mathrm{W}, 682 \mathrm{~m}$ depth for the Colloid Exchangeability Experiment), and 3)

150 in June 2018 on a Galveston Bay cruise aboard the R/V Trident (Station 3, 29.45 $\mathrm{N}, 94.87^{\circ} \mathrm{W}, 1$

$151 \mathrm{~m}$ depth) for the Colloid Preservation Experiment. Briefly, samples collected aboard the ARSV

152 Laurence M. Gould were collected using a trace metal clean CTD rosette loaded with 12 x 12 L

153 Niskin-X bottles from stations close to the coast thought to be rich in colloids. Samples collected

154 aboard the USCGC Healy followed established trace metal sampling protocols [Cutter et al.,

155 2010] using a trace-metal clean Seabird CTD rosette mounted with 24 x 12 L GO-FLO (General

156 Oceanics) bottles. The surface-water samples from Galveston Bay were collected using a trace-

157 metal clean PTFE double diaphragm pump (Cole Parmer) fitted with acid-cleaned Bev-A-Line

158 tubing (1/4 in, Cole Parmer) at stations thought to be rich in colloids. In all cases, samples were

159 initially filtered through $0.2 \mu \mathrm{m}$ AcroPak-200 polyethersulfone membrane filter capsules (Pall)

160 and collected, following three 10\% volume rinses, in LDPE Nalgene bottles previously cleaned

161 using hydrochloric acid ( $\mathrm{HCl}$, trace metal grade, $1 \mathrm{M})$ and ultrapure Milli-Q (MQ, Millipore)

162 water at $60^{\circ} \mathrm{C}$ [Fitzsimmons and Boyle, 2012].

\section{Ultrafiltration methods}

In each of the colloidal preservation and exchangeability experiments, standard protocol for the ultrafiltration of seawater was completed using a trace metal clean cross flow filtration system (CFF) [Fitzsimmons and Boyle, 2014b]. This CFF system employed a Millipore Pellicon XL regenerated cellulose filter with a nominal weight cutoff of $10 \mathrm{kDa}(\sim 3 \mathrm{~nm}$ for spherical proteins, [Erickson, 2009]) and a Cole Parmer Masterflex pump with all fluorinated ethylene propylene (FEP) tubing. Prior to the research cruises, new Pellicon filters were first cleaned with $1 \mathrm{~L}$ of $0.24 \mathrm{M} \mathrm{HCl}$ (Optima Fisher Scientific), which was allowed to recirculate through the

174 through the system followed by $100-500 \mathrm{~mL}$ of sample seawater (as much as the experimental

175 volume allowed) to condition the system and allow for an accurate flow rate calibration. Total

176 flow rate was calibrated to $25 \mathrm{~mL} / \mathrm{min}$, and permeate and retentate flows were subsequently

177 equalized to $12.5 \mathrm{~mL} / \mathrm{min}$ and recorded for accurate determination of the colloid concentration

178 factor and recovery. 
In this paper, all ultrafiltration via CFF was "single-pass," meaning that the retentate solutions were not recycled back into the feed solution for cumulative ultrafiltration; instead, we treat all results as traditional filtrations but with a small pore size, which minimizes artifacts associated with common $\mathrm{CFF}$ approaches that pass sample retentate over the same filter multiple times. Critically, by maximizing flow rate through our CFF system, we minimize the height of our concentration polarization layer and associated filtration biases that were observed in early CFF ultrafiltration experiments for metals [Buffle et al., 1992], and also by keeping sample volumes low and acid cleaning well between samples, we avoid variations in the permeate metal concentrations over time, which were so often observed in earlier studies (e.g. [Wen et al., 1996]). In our system, soluble metal (sMe) concentrations are therefore defined as the concentration measured in the permeate solution, or what passes through the $10 \mathrm{kDa}(\sim 0.003$ $\mu \mathrm{m})$ membrane. Colloidal metal (cMe) concentrations are calculated as the mass balance difference between dissolved metal $(\mathrm{dMe})$ and sMe concentrations $([\mathrm{cMe}]=[\mathrm{dMe}]-[\mathrm{sMe}])$, which assumes that any metal lost to the CFF system (during imperfect recovery from the CFF system) is lost from the colloidal size fraction only, not the soluble size fraction. This was

194 confirmed in Fitzsimmons and Boyle [2014a] for Fe using Pellicon CFF filters, where Fe losses

195 were attributed mostly to colloidal Fe trapping inside the membrane itself. The cMe fraction is

196 calculated as the cMe concentration divided by the dMe concentration $(\% \mathrm{cMe}=[\mathrm{cMe}] /[\mathrm{dMe}])$.

197 The recovery is calculated as in Fitzsimmons and Boyle [2014a] and assesses the metal yield in

198 the permeate + concentrated retentate solutions compared to the initial dMe concentration fed into the CFF system.

\section{Experimental methods}

1. Colloid preservation experiment - Water collected from a near-bottom depth of $1320 \mathrm{~m}$ near Palmer Station (West Antarctic Peninsula) was used to assess whether seawater samples can

204 be preserved over time for cMe size partitioning determination (Figure 1). Four $250 \mathrm{~mL}$ bottles, two $60 \mathrm{~mL}$ bottles, and one $4 \mathrm{~L}$ bottle of $0.2 \mu \mathrm{m}$-filtered (Acropak 200, Pall) seawater were filled directly from a trace metal clean Niskin-X bottle following three $10 \%$ rinses of all bottles, caps, and threads. The two $60 \mathrm{~mL}$ bottles were immediately acidified and represent the initial dissolved metal concentrations (T0). The $4 \mathrm{~L}$ bottle was left at room temperature for immediate ultrafiltration into two $60 \mathrm{~mL}$ permeate $(\mathrm{P} \mathrm{T0})$ and two $60 \mathrm{~mL}$ retentate $(\mathrm{R} \mathrm{T0})$ solutions. Two

211 remaining two $250 \mathrm{~mL}$ bottles were preserved in the dark at $-20^{\circ} \mathrm{C}$ (frozen) and thawed to room 212 temperature before ultrafiltration.

213 To assess the colloidal size partitioning, ultrafiltration of the $250 \mathrm{~mL}$ preserved (frozen or

214 RT) samples was completed after 7 days (T7) and after 21 days (T21), using the CFF methods 
215 above. Each time point yielded one $60 \mathrm{~mL}$ bottle of non-filtered, "poured" seawater, to record

216 the dMe concentrations remaining in the bottle at that time point (minus any adsorption to bottle 217 walls), one $60 \mathrm{~mL}$ bottle that was filled with CFF-ultrafiltered permeate solution (P), which

218 contains no colloids and only truly soluble species, and one $60 \mathrm{~mL}$ bottle that was filled with

219 ultrafiltered retentate solution $(\mathrm{R})$, which contained some soluble species and the concentrated 220 colloids (for CFF recovery determination).

221 We repeated this experiment with additional replicates and time points using the same

222 procedure but with surface water collected from Galveston Bay. To better constrain the

223 variability imparted by the CFF ultrafiltration itself, triplicate initial dMe (T0) were collected as

224 well as triplicate CFF-ultrafiltered permeate (P T0) and retentate (R T0) samples. Replicate 250

$225 \mathrm{~mL}$ samples were stored frozen and at room temperature and were then ultrafiltered after 2 days

226 in duplicate (T2), after 9 days (T9, only one replicate each), and after 23 days (T23, one replicate

227 for room temperature, duplicate for frozen treatment). All samples in both experiments were

228 acidified to $0.012 \mathrm{M} \mathrm{HCl}$ (Optima) following their final filtration.

2. Colloid exchangeability - Water collected from a near-bottom depth $(682 \mathrm{~m})$ in

230 Marguerite Bay on the West Antarctic Peninsula was used to determine colloid metal

231 exchangeability ("re-formation") kinetics using the methods illustrated in Figure 2. Water was

232 filtered directly from a trace metal clean Niskin-X bottle through a $0.2 \mu \mathrm{m}$ filter (Acropak 200,

233 Pall) into a 4 L LDPE bottle following three $10 \%$ rinses of the bottle, cap, and threads. This

234 filtered seawater was immediately sub-sampled into two $60 \mathrm{~mL}$ bottles for dMe determination

235 (T0), whilst additional seawater was immediately ultrafiltered into two $60 \mathrm{~mL}$ bottles for

236 permeate (P T0) and two $60 \mathrm{~mL}$ bottles for retentate (R T0), as well as one $2 \mathrm{~L}$ bottle of just

237 permeate solution. The $2 \mathrm{~L}$ bottle was the "incubation bottle" in which colloids were initially

238 removed but might be re-forming ("exchanging with" or "aggregating from" the soluble phase)

239 over time. This bottle was stored in the dark at room temperature until further processing at each

240 time point.

241 After 14 hours, seawater from the bulk $2 \mathrm{~L}$ permeate sample was poured into $60 \mathrm{~mL}$

242 bottles (P T14 "pour") to capture the dMe concentrations in the bulk $2 \mathrm{~L}$ bottle, which excludes

243 any metals lost to bottle wall adsorption. Solution from the $2 \mathrm{~L}$ bulk bottle was ultrafiltered again

244 into permeate and retentate fractions (PP, PR at T14). This procedure was repeated at 24, 48, and

24570 hours (T24, T48, and T70, respectively). All $60 \mathrm{~mL}$ samples were subsequently acidified to

$2460.012 \mathrm{M} \mathrm{HCl}$ (Optima).

247 3. Adsorption/desorption - Adsorption and desorption of metals was tested using LDPE

248 bottles of two volumes, $250 \mathrm{~mL}$ and $125 \mathrm{~mL}$, to quantify any effect of surface area to volume

249 ratio $(\mathrm{SA}: \mathrm{V})$ on metal adsorption. Seawater for these experiments was collected at $100 \mathrm{~m}$ depth

250 in the Western Arctic Ocean. 
For the adsorption experiment (Figure 3), seawater was filtered from a GO-FLO bottle through a $0.2 \mu \mathrm{m}$ filter (Acropak-200, Pall) into a trace metal clean $10 \mathrm{~L}$ carboy, homogenized, and then immediately subsampled into eighteen $250 \mathrm{~mL}$ bottles and eighteen $125 \mathrm{~mL}$ bottles

254 following three $10 \%$ rinses of the insides, caps, and threads, with no headspace. For the initial 255 time point (T0), three $250 \mathrm{~mL}$ and three $125 \mathrm{~mL}$ bottles were immediately acidified $(0.024 \mathrm{M}$ $256 \mathrm{HCl}$, Optima). The remaining bottles were stored unacidified at room temperature in the dark 257 (black bags) for different time periods during which metals could adsorb to the bottle walls. At each subsequent time point, three $250 \mathrm{~mL}$ and three $125 \mathrm{~mL}$ samples were poured into new, acidcleaned 250 and $125 \mathrm{~mL}$ bottles, respectively, and acidified, which leaves any metals adsorbed to the original bottle walls in the original bottles. This was repeated at $4,8,16$, and 24 hours. Additionally, three $250 \mathrm{~mL}$ and three $125 \mathrm{~mL}$ samples were set aside as "long term" storage time points. They were transferred to new bottles and acidified $(0.024 \mathrm{M} \mathrm{HCl}$, Optima) at $\sim 40$ months. For the desorption experiment (Figure 3), water collected from the same depth was 0.2 $\mu \mathrm{m}$ filtered from a separate GO-FLO bottle and placed into another $10 \mathrm{~L}$ carboy, homogenized, and then directly sub-sampled into twelve $250 \mathrm{~mL}$ bottles and twelve $125 \mathrm{~mL}$ bottles following three $10 \%$ rinses of the insides, caps, and threads, with no headspace. All bottles were left at room temperature in the dark, unacidified (to allow for metal adsorption to bottle walls) for $\sim 22$ months until acidification (0.012 M HCl, Optima). Immediately following acidification, two 250 $\mathrm{mL}$ and two $125 \mathrm{~mL}$ bottles were poured off into four fresh $250 \mathrm{~mL}$ bottles, representing the initial time point (T0). This T0 time point captured any dMe remaining in solution as well as any $\mathrm{dMe}$ that had rapidly desorbed from bottle walls flowing acidification. This process of pouring into a new clean bottle was repeated after 1,3, 7.5, 12, and 20 weeks to measure the kinetics of metal desorption from bottle walls as a function of bottle SA:V ratio.

\section{Metal analysis}

Samples were analyzed for $\mathrm{Mn}, \mathrm{Fe}, \mathrm{Co}, \mathrm{Ni}, \mathrm{Cu}, \mathrm{Zn}, \mathrm{Cd}$, and $\mathrm{Pb}$ at least 1 month following acidification using an offline isotope dilution and pre-concentration method on a SeaFAST-pico system (ESI, Omaha), modified from Lagerström et al. [2013]. This method is described for Zn in Jensen et al. [2019] but is expanded here for the other metals. Briefly, a 10 mL sample aliquot was weighed and spiked with an isotope spike mixture containing $\left[{ }^{5} \mathrm{Fe}\right]=$ $480.5 \mathrm{nM},\left[{ }^{\left[{ }^{2} \mathrm{Ni}\right.}\right]=1455.8 \mathrm{nM},\left[{ }^{6{ }^{\circ} \mathrm{Cu}}\right]=687.5 \mathrm{nM},\left[{ }^{\circ} \mathrm{Zn}\right]=709.6 \mathrm{nM},\left[{ }^{206} \mathrm{~Pb}\right]=44.7 \mathrm{nM}$, and $\left[{ }^{1{ }^{\circ 1}} \mathrm{Cd}\right]$ $=449.6 \mathrm{nM}$ and loaded into the SeaFAST system. For monoisotopic metals Mn and Co, a standard was created where $[\mathrm{Mn}]=452.80 \mathrm{nmol} / \mathrm{kg}$, and $[\mathrm{Co}]=12.01 \mathrm{nmol} / \mathrm{kg}$, and this standard was used to create a 6-point standard curve spanning 0 to $10 \mathrm{nmol} / \mathrm{kg}$ for $\mathrm{Mn}$ and 0 to 0.27 $\mathrm{nmol} / \mathrm{kg}$ for Co. It is important to note here that samples were not UV oxidized and thus the Co measured represents the "labile" fraction. Samples were then buffered in line with an ammonium 
287 acetate buffer (Optima, Fisher Scientific) prepared to $\mathrm{pH} \sim 7.4$, which when mixed with the 10

$288 \mathrm{~mL}$ of spiked sample at a flow rate of $350 \mu \mathrm{L} / \mathrm{min}$ results in a buffered sample $\mathrm{pH}$ of $6.2 \pm 0.3$

289 [Sohrin et al., 2008]. This solution was immediately loaded onto a column containing Nobias-

290 chelate PA1 resin and rinsed with ultrapure water to remove salts. The sample was subsequently

291 back-eluted with 10\% (v/v) nitric acid (Optima, Fisher Scientific) to yield $400 \mu \mathrm{L}$ of eluent,

292 representing a 25-fold sample pre-concentration. These eluents were analyzed in low $(\mathrm{Pb}$ and

$293 \mathrm{Cd}$ ) and medium ( $\mathrm{Fe}, \mathrm{Zn}, \mathrm{Ni}, \mathrm{Mn}, \mathrm{Cu}$, and $\mathrm{Co}$ ) resolution on a Thermo Element XR high

294 resolution inductively coupled plasma mass spectrometer (HR-ICP-MS) at Texas A\&M

295 University in the R. Ken Williams Radiogenic Isotope Facility. Table 1 summarizes the detection

296 limit and reference sample analyses to demonstrate the accuracy and precision of the

297 measurements.

298

299 Results

300 1. Colloid Preservation Experiment: Can soluble/colloidal size partitioning be preserved over

301 time by storing seawater frozen or at room temperature?

302 The goal of this experiment was to assess whether the natural size partitioning of marine

303 metals into soluble and colloidal fractions could be preserved prior to ultrafiltration over a

304 timescale of weeks under room temperature or frozen conditions. This would allow seawater to

305 be collected in the field, stored using an ideal preservation method, and then ultrafiltered back in

306 the laboratory when more time allows for optimal ultrafiltration conditions. This experiment was

307 completed twice: first using water from the West Antarctic Peninsula continental shelf (the

308 Southern Ocean experiment using near-bottom seawater in Palmer Canyon), and then with

309 increased experimental replication using surface water from Galveston Bay, Texas.

310 In the Southern Ocean experiment (Figure 4; salinity $=34.70, \mathrm{~T}=1.48^{\circ} \mathrm{C}$ ), the samples

311 stored at room temperature exhibited a statistically significant decrease ( $t$-test, two-tailed,

312 heteroscedastic, $p<0.05)$ in $\mathrm{dFe}$ concentration of $75 \%$ after just 7 days, likely from adsorption

313 of $\mathrm{dFe}$ to bottle walls (see Adsorption Experiment results below), and continued to decrease

314 through 21 days. In contrast, when stored frozen, the initial dFe concentration was fairly well

315 preserved over 21 days, with no significant decrease $(<5 \%)$, suggesting that wall adsorption does

316 not occur to a significant extent if seawater is frozen immediately. Additionally, when frozen the

$317 \mathrm{dFe}$ size partitioning was also well preserved compared to initial ultrafiltration. This can be seen

318 by relatively constant sFe concentrations over time and comparable \% cFe after 7 days (63\%)

319 and even 21 days (67\%), compared to the initial partitioning (62 $\pm 2 \%)$. These results suggest

320 that freezing filtered seawater can preserve both the $\mathrm{dFe}$ concentration and its size partitioning

321 into soluble/colloidal fractions relatively well (compared to samples ultrafiltered immediately) 
322 over the timescale of weeks. In contrast, storing samples at room temperature allows for wall 323 adsorption that prevents the preservation of dFe concentrations over time.

324 To compare these results to a seawater sample with different physicochemical Fe 325 speciation, the experiment was repeated in Galveston Bay (Figure 4; salinity $=26.50, \mathrm{~T}=$ $32630.93^{\circ} \mathrm{C}$ ) with two improvements: 1) more size partitioning replicates at each time point to 327 improve statistical strength in comparisons between time points, and 2) more sampling time 328 points: T2 at 2 days, T10 at 10 days, and T23 at 23 days, which is most similar to the T21 time 329 point from the first Southern Ocean experiment. Unlike in the Southern Ocean experiment, $\mathrm{dFe}$ 330 concentrations were not well preserved even when frozen (Figure 4a, right), dropping 17\% from $3312.36 \pm 0.04 \mathrm{nmol} / \mathrm{kg}(\mathrm{n}=3)$ to $1.99 \mathrm{nmol} / \mathrm{kg}$ in the frozen treatment after 10 days; this is similar 332 magnitude to the $\mathrm{dFe}$ loss observed in the room temperature treatment. However, despite these $333 \mathrm{dFe}$ losses, the size partitioning of $\mathrm{dFe}$ was well maintained over time in both the room 334 temperature and frozen treatments, with the exception of two likely contaminated permeate 335 samples (RT T2 and frozen T10, which were anomalous for several metals). This difference 336 between experiments suggests that variation in the physicochemical speciation of Fe between 337 sites can affect adsorption to bottle walls and/or long-term colloid exchangeability with other 338 species in solution, both of which would affect the ability to preserve a sample over time.

339 However, both experiments together suggest that storing samples frozen can fairly well preserve $340 \mathrm{dFe}$ size partitioning into soluble and colloidal phases.

341 Like Fe, Mn and Co both show little sorption loss to bottle walls $(<10 \%)$ in the frozen 342 treatment compared to room temperature (Figure 4), making the frozen storage method the best 343 method for size partitioning preservation of these metals. However, while $\mathrm{Zn}, \mathrm{Ni}, \mathrm{Cu}, \mathrm{Cd}$, and $\mathrm{Pb}$ 344 display minimal change in their dissolved concentrations over time, they all suffer reductions in 345 permeate "soluble" concentrations, usually even by 7 days. Thus colloids were being generated 346 in solution due to aggregation over the duration of the experiment. This was especially true for $347 \mathrm{Cd}$, which showed substantial colloidal aggregation from 0 to $>20 \%$ colloidal $\mathrm{Cd}$ at the 348 Galveston Bay site. However, in the Southern Ocean experiment, this was also true for Ni and 349 particularly true for $\mathrm{Zn}$ and $\mathrm{Pb}$, where the colloid fraction increased from $20 \%$ to $>90 \%$ by 21 350 days. Interestingly, this effect was more prominent for frozen samples (Figure 4d and e, 351 respectively).

352 What explains the poor preservation of dMe size partitioning for all metals besides Fe, $353 \mathrm{Mn}$, and Co under frozen conditions? Several factors must be considered, including metal 354 sorption to bottle walls (which could favor soluble or colloidal metals), natural colloidal 355 aggregation over time (which could be dependent on preservation conditions including 356 temperature), and artifacts related to the ultrafiltration process. While we explore bottle wall 
357 adsorption and colloidal formation kinetics in detail in the next two experiments, we will first 358 preview some patterns here based on these initial Colloid Preservation Experiments.

Sorption to bottle walls was evident in the room temperature treatments for dissolved $\mathrm{Fe}$, $\mathrm{Zn}, \mathrm{Co}, \mathrm{Pb}, \mathrm{Ni}$, and $\mathrm{Mn}$, but was much more severe for Fe and $\mathrm{Co}(66 \%$ and $69 \%$ after 21 days, respectively) than for $\mathrm{Zn}(16 \%), \mathrm{Pb}(25 \%), \mathrm{Ni}(6 \%)$, and $\mathrm{Mn}(4 \%)$. We also note that these statistics are for the Southern Ocean samples, which in general showed more bottle wall adsorption than the Galveston Bay samples. This can be attributed to differences between sites in either initial sample temperature and/or physicochemical metal speciation. It is known that sorption of metals to bottle walls is an exothermic process that is hastened in samples kept at colder temperatures [Bartell et al., 1951; Fitzsimmons and Boyle, 2012]. It is not clear whether smaller soluble-sized or colloidal-sized species are favored during bottle wall adsorption, since for $\mathrm{Co}$ and $\mathrm{Mn}$ the dissolved and permeate concentrations appeared to decrease by similar amounts, implicating soluble $\mathrm{Co}$ and $\mathrm{Mn}$ in wall sorption, but for the other metals ( $\mathrm{Zn}, \mathrm{Ni}$ and $\mathrm{Pb}$ in particular) the permeate concentrations decreased much more than the dissolved concentrations, possibly implicating wall sorption of the soluble phase or colloid formation. Additionally, soluble-colloidal exchange cannot be precluded, making any pattern difficult to attribute specifically to adsorption of soluble or colloidal metals alone.

It should also be noted that for the two metals with the greatest ingrowth of colloids over time $(\mathrm{Zn}$ and $\mathrm{Pb})$ in the Preservation Experiment, the recovery of these metals through the $\mathrm{CFF}$ system also decreased over time from $>90 \%$ in samples ultrafiltered immediately (T0) to $<30 \%$ recovery after 21 days for the Southern Ocean samples. Thus, some of the "colloidal ingrowth" in these experiments could be misattributed and instead be caused by increasing soluble metal losses to the CFF system over time. The behavior of metals other than Fe in these CFF filters has not been well constrained, as the original CFF methods development and testing focused solely on Fe [Fitzsimmons and Boyle, 2014b]. In fact, an earlier study by [Wen et al., 1996] using a recirculating CFF system with different ultrafilter materials found molecular weight shifts in trace metal colloids during storage at room temperature, indicating potential aggregation over the course of hours at room temperature. However, even within our own experiments, it would appear that aged samples do not perform as reliably in the CFF system compared to fresh samples, since reductions in recovery were observed for all of the dissolved metals measured in the Southern Ocean experiment as a result of sample storage. In contrast, CFF recovery was generally higher and overall much more constant in the higher temperature Galveston Bay samples. Notably, the differences in recovery under frozen or room temperature conditions was not statistically different for any of the metals, so while we suggest here that there is a sample temperature effect on CFF recovery, which may help explain the differences between the Southern Ocean vs. Galveston Bay results, we cannot conclusively prove temperature causation. 
In summary, the differences in dissolved metal concentrations and size partitioning

394 preservation between the Southern Ocean and Galveston Bay samples can likely be attributed to

395 two major factors: natural physicochemical speciation differences between samples and

396 ultrafiltration artifacts. Natural physicochemical speciation refers to the native physical and

397 chemical forms that the colloids originally had in seawater. In the Southern Ocean, previous

398 studies point to potential sedimentary sources and/or resuspension supplying both particulate and

399 dissolved Fe to Palmer Canyon bottom waters [Sherrell et al., 2018], as well as a high abundance

400 of Fe-binding ligands with benthic sources [Gerringa et al., 2008] that may serve to stabilize dFe.

401 In contrast, in an estuarine environment such as Galveston Bay, we would expect many inorganic

402 dFe nanoparticles coated in humic-like organics [Powell et al., 1996; Wen et al., 2008]. These

403 two samples thus have quite different physicochemical metal speciation and thus it is not

404 surprising that they behave differently upon preservation or when processed using our CFF

405 system. Furthermore, prior studies have suggested that Fe solubility increases at colder

406 temperatures and that $\mathrm{dFe}$ samples that were frozen and thawed have a higher solubility

407 [Schlosser et al., 2012]. In this case, Fe would be more prone to stay solubilized under frozen

408 conditions but also natively in a cold climate. This would in turn play into any filtration artifacts,

409 which may be influenced by the original physicochemical speciation of the sample, as well as

410 how it behaves when aged/warmed over time [Schlosser et al., 2011].

412 2. Colloid Exchangeability Experiment: Do colloids "grow back" after removal via 413 ultrafiltration, and if so, how fast?

414 The goal of this experiment was to determine the rate of potential colloid re-formation

415 (aggregation from soluble phase) at room temperature over 70 hours after all colloids were

416 removed from a near-bottom Southern Ocean sample via ultrafiltration. Aggregation of material

417 from the soluble to the colloidal size fraction could be stimulated by interactions with the bottle

418 walls, organic coagulation [Wilkinson et al., 1997], gel formation [Chin et al., 1998], and/or the

419 so-called "Brownian pumping" of soluble-sized species [Honeyman and Santschi, 1989; Wen et

420 al., 1997]. At each time point after colloids were removed from the permeate solution at T0, any

421 potential adsorption to bottle walls was monitored by pouring off a subsample of the original

422 permeate solution, and then this original permeate solution was also re-ultrafiltered to assess

423 whether colloids had re-formed over time. If there was no generation of colloids, the re-

424 ultrafiltered permeate should have equaled the "poured" permeate concentration at each time

425 point. This was only true for dissolved $\mathrm{Mn}$ and $\mathrm{Cd}$, which had negligible colloids in the original

426 sample, and no additional colloids formed over the 70 hour time period that was studied (Figure

$4275 \mathrm{~d}, \mathrm{~h})$. 

aggregation over the 70 hour experiment after they were removed at T0 (Figure 5). For Fe, the Southern Ocean sample originally had $58 \%$ of its $\mathrm{dFe}$ in the colloidal size fraction $(\mathrm{cFe}=0.75$ $\mathrm{nmol} / \mathrm{kg}$ ), and after the colloids were removed at $\mathrm{T} 0, \mathrm{cFe}$ returned to $40 \%$ of dissolved after only 14 hours $(\mathrm{cFe}=0.21 \mathrm{nmol} / \mathrm{kg})$ and eventually exceeded the original fraction to $74 \%$ after 70 hours $(\mathrm{cFe}=0.46 \mathrm{nmol} / \mathrm{kg})$. Additional results from an identical experiment at Station ALOHA $\left(22.75^{\circ} \mathrm{N}, 158.00^{\circ} \mathrm{W}, 24\right.$ September $2013,800 \mathrm{~m}$; sampling methods in [Fitzsimmons et al., 2015a]) demonstrated that Fe colloids can re-aggregate in as little as 3 hours and approach the initial \% colloidal partitioning after only 22 hours (Figure 5e). This supports the conclusion that cFe aggregation occurs almost immediately and continues over time, likely attributed to interactions between the soluble and colloidal organic compounds that complex Fe in seawater, as well as possible self-assembly [Ding et al., 2008]. While we do not have direct chemical speciation measurements at these near-bottom study sites, the only available literature data from surface waters of the West Antarctic Peninsula and coastal Antarctica indicate that ligands that may form complexes with $\mathrm{Fe}$ are present but are often saturated and thus not uniformly in excess of Fe in this region in the surface ocean [Buck et al., 2010; Thuróczy et al., 2012].

The colloidal Fe re-aggregation kinetics pattern was replicated for $\mathrm{Ni}$ and $\mathrm{Zn}$, except that for $\mathrm{Ni}$ and $\mathrm{Zn}$ both the colloidal concentrations and $\%$ colloidal $\mathrm{Ni}$ and $\mathrm{Zn}$ exceeded the original levels by 14 and 24 hours, respectively; in contrast, it took Fe 70 hours to exceed the original $58 \% \mathrm{cFe}$. Thus, Ni and $\mathrm{Zn}$ were particularly affected by the removal of colloidal species at the start of the experiment, and their re-aggregation kinetics were especially fast. This must be related to $\mathrm{Ni}$ and $\mathrm{Zn}$ themselves and/or the organic ligands that bind them [Van den Berg and Nimmo, 1987; Bruland, 1989], since $\mathrm{Fe}, \mathrm{Cu}$, and $\mathrm{Pb}$ did not behave similarly in the same samples. For $\mathrm{Cu}$ and $\mathrm{Pb}$, colloids did re-aggregate by 14 hours following colloid removal, but $\mathrm{cCu}$ never reached its original \% colloidal $\mathrm{Cu}$, even after 70 hours, while $\mathrm{dPb}$ quickly returned to the size partitioning of the original samples.

Thus, it appears that the metals studied here that have a substantial natural colloidal fraction in seawater $(\mathrm{Fe}, \mathrm{Cu}, \mathrm{Zn}, \mathrm{Ni}$, and $\mathrm{Pb}$ ) will re-aggregate to form colloids in as short as 14 hours. However, the extent to which those colloids re-form varies, as often the re-formed \% colloidal metal and the colloidal metal concentrations do not match the initial results. We hypothesize that organic aggregation/coagulation kinetics are involved, since the one element most likely to exist as a free cation (Mn, [Oldham et al., 2017]) showed no colloidal character in

461 [Rue and Bruland, 1995; Wu and Luther III, 1995; Moffett and Dupont, 2007], yet Cu did not re462 form colloids to the same extent as Fe. Our knowledge of organic complexation of some of the 463 other metals, like $\mathrm{Zn}, \mathrm{Cd}$, and $\mathrm{Pb}$, however, is too poor to speculate further on the direct 
464 pathways of colloidal aggregation, except to say that organic aggregation is likely involved and our data demonstrate the extent to which these metals can re-aggregate.

3. Adsorption Experiment: How quickly are dissolved metals lost from solution to bottle wall adsorption in the absence of seawater acidification?

The goal of this experiment was to quantify the rate of adsorptive loss of metals onto LDPE bottle walls over 24 hours, which is a relevant timescale during which filtered seawater might be stored in holding bottles awaiting further processing. The results are shown in Figure 6 , where the $\% \mathrm{dMe}$ change from the initial concentration (indicated by a grey bar) are shown. Triplicate sampling allowed obviously contaminated samples to be removed from the averages used to calculate $\%$ metal loss to bottle walls.

Prior studies on bottles made of plastics other than LDPE indicate that the higher SA:V of smaller bottles will cause greater adsorptive Fe losses [Fischer et al., 2007; Fitzsimmons and Boyle, 2012]. Indeed, the $\mathrm{SA}: \mathrm{V}$ ratio of our $125 \mathrm{~mL}$ bottles is higher than our $250 \mathrm{~mL}$ bottles $\left(0.838 \mathrm{~cm}^{-1}\right.$ versus $\left.0.760 \mathrm{~cm}^{-1}\right)$, providing more area per volume onto which metals can adsorb. The Adsorption Experiment data here on LDPE bottles show that, as expected, more adsorption occurred in the smaller $125 \mathrm{~mL}$ bottles compared to the $250 \mathrm{~mL}$ bottles for $\mathrm{Co}, \mathrm{Cu}, \mathrm{Zn}$ and $\mathrm{Ni}$ over 40 months. DFe also showed higher \% loss onto the $125 \mathrm{~mL}$ bottles until 40 months, when surprisingly the adsorption onto $250 \mathrm{~mL}$ bottle walls (91\% loss) surpassed that on the $125 \mathrm{~mL}$ bottle walls (75\%). This could indicate that the dependence of bottle sorption on SA:V ratio is not the most significant factor in sorption, particularly when the SA:V ratios are comparable, as in our 125 and $250 \mathrm{~mL}$ bottles. However, these results do support prior suggestions that if storage in a plastic bottle over time is necessary, it is preferable to use larger bottle sizes (lower $\mathrm{SA}: \mathrm{V})$ to help reduce metal sorption losses to bottle walls.

Prior studies also suggest that metal sorption to bottle walls appears to be affected by bottle material. For example, Fe adsorbed the most over $\sim 72$ hours in quartz bottles $(99 \%$, [Fischer et al., 2007]), compared to HDPE bottles (29-60\%, [Schlosser et al., 2011; Fitzsimmons and Boyle, 2012]), and PTFE bottles (40-60\%, [Schlosser and Croot, 2008]) in prior studies. Adsorption onto LDPE bottles had not been explored previously, despite their being the bottle of choice for marine trace metal studies since the GEOTRACES era [Cutter et al., 2010], yet the second result of our Adsorption Experiment showed that LDPE bottle walls did promote some wall adsorption of dFe over 24 hours, which continued until 40 months after sample collection for both sizes. Our data show that sorption losses from unacidified samples to LDPE bottles are generally low over the first 24 hours and only statistically significant for dissolved $\mathrm{Fe}, \mathrm{Co}, \mathrm{Ni}$, $\mathrm{Zn}$, and Cd after 40 months (Figure 6). Previously, dFe was adsorbed to HDPE bottle walls at a ratio of $0.878 \%$ per SA:V (cm-1) ratio [Fitzsimmons and Boyle, 2012] over 15.5 hours, which 
500 would predict that 0.20 and $0.15 \mathrm{nmol} / \mathrm{kg}$ of $\mathrm{dFe}$ would have adsorbed onto $125 \mathrm{~mL}$ and $250 \mathrm{~mL}$

501 HDPE bottle walls by 16 hours. However, only 0.16 and $0 \mathrm{nmol} / \mathrm{kg}$ were actually adsorbed,

502 respectively, onto the LDPE bottle walls used in this study after 16 hours, indicating that

503 adsorption of metals to LDPE bottle walls is lower than adsorption to HDPE bottle walls, even

504 with identical acid cleaning.

505 The third result of the Adsorption Experiment was that wall adsorption to LDPE bottles

506 can now be extended to other metals beyond Fe, with significant losses observed over just 16

507 hours for dissolved $\mathrm{Co}, \mathrm{Ni}, \mathrm{Cu}, \mathrm{Zn}$, and $\mathrm{Cd}$ (Figure 6). While wall losses of dFe have been

508 studied in the past, losses of the other metals have been poorly constrained in any bottle type. Of

509 the available data, one study showed that $\mathrm{dCu}$ had an adsorptive loss of $1.6 \%$ onto fluorinated

510 ethylene (poly)propylene Nalgene bottles over the course of 2 hours, while dCd showed almost

511 no adsorption in seawater samples spiked with $\mathrm{Cu}, \mathrm{Cd}$, and $\mathrm{Pb}$ [Cuculić and Branica, 1996]. No

512 conclusive kinetic data for dissolved Ni, Mn, Zn, or Co exists from prior studies despite the fact

513 that we now routinely collect and measure these dissolved metals in seawater. In this study,

514 dissolved $\mathrm{Fe}, \mathrm{Co}$, and $\mathrm{Zn}$ showed the largest losses over 40 months in both bottle sizes, ranging

515 from 22 to $91 \%$ loss (Figure 6 a,b,c). $\mathrm{Ni}$ and $\mathrm{Cu}$ also showed modest losses over this timescale (6

516 to $8 \%$ and 4 to $9 \%$ loss, respectively), despite showing almost no loss for Ni after 24 hours. Wall

517 losses of dissolved $\mathrm{Mn}$ and $\mathrm{Cd}$ were negligible $(<5 \%)$, even after being left unacidified for 40

518 months.

519

520 4. Desorption Experiment: Once samples have been acidified, how quickly do metals desorb

521 from bottle walls?

522 The goal of this experiment was to examine the kinetics of metal desorption from 125

523 and $250 \mathrm{~mL}$ LDPE bottle walls and thus assess how long samples that are thought to have

524 suffered losses to bottle walls must be acidified to desorb the metals. We set up both the

525 Adsorption and Desorption Experiments using seawater from the same $100 \mathrm{~m}$ depth in the Arctic

526 Ocean so that we could compare concentrations at time points in both experiments to the same

527 concentration (T0 of adsorption experiment, Figure 6, grey bar), which was the initial filtered

528 seawater acidified immediately upon collection. The Desorption Experiment bottles were left

529 unacidified for 22 months during which time metals were allowed to adsorb onto the bottle walls.

$530 \quad$ The Adsorption Experiment showed that dissolved $\mathrm{Fe}, \mathrm{Co}, \mathrm{Ni}, \mathrm{Cu}$ and $\mathrm{Zn}$ were

531 significantly adsorbed to LDPE bottle walls after spending 40 months unacidified; however, the

532 Desorption Experiment showed that the desorption kinetics of each of these metals back to their

533 initial concentration varied significantly. For instance, $30-40 \%$ of the dissolved $\mathrm{Fe}$ and Co that

534 had adsorbed over 40 months desorbed immediately, but remained 7-19\% lower than their initial 
535 concentrations 20 weeks after acidification (Figure 6a, b); thus, we never recovered all of the lost

$536 \mathrm{Fe}$ or Co. DFe also showed some temporally variable desorption or exchange, as it desorbed to

537 within $11 \%$ of the initial concentration by 12 weeks only to fall again to $19 \%$ below the initial

538 concentration at 20 weeks. In contrast, dissolved $\mathrm{Ni}, \mathrm{Cu}$, and $\mathrm{Zn}$ all desorbed back to within

$539 \pm 10 \%$ of the original sample concentration immediately upon acidification. However, all three

540 were still significantly different from the initial concentration after 20 weeks in the $250 \mathrm{~mL}$

541 bottles only. Dissolved Cd and Mn had insignificant desorption rates, but they also had

542 insignificant adsorption to bottle walls, indicating that the timescale of acidification plays little to

543 no role in the storage and analyses of these two metals.

\section{Discussion and Implications}

$546 \quad$ Based on the experimental results described above, we first make several

547 recommendations for the collection and handling of dissolved and particularly colloidal trace

548 metals samples in seawater. Then, we discuss some implications for the physicochemical

549 speciation of dissolved metals in the ocean.

$550 \quad$ We recommend that:

551 1. Seawater should only be preserved for Fe size partitioning, not the size partitioning of any of the other metals, and only if stored seawater samples are preserved frozen at $-20^{\circ} \mathrm{C}$ immediately upon collection;

554

555

556

557

558

559

560

561

562

563

564

565

566

567

568

2. Careful attention be given to the source and thus potential native conditions/physicochemical speciation of samples analyzed for metal size partitioning, as this appears to affect the preservation of metal speciation over time as well as colloid recovery during the ultrafiltration process;

3. Filtered seawater samples that require ultrafiltration should be ultrafiltered as soon as possible but no later than 24 hours after initial filtration in order to avoid wall adsorption to bottle walls and/or exchange between the soluble and colloidal size fractions;

4. Seawater samples that will be stored in $125 \mathrm{~mL}$ or $250 \mathrm{~mL}$ LDPE bottles should be acidified as soon as possible (within a few hours at most) to avoid adsorptive wall losses of dissolved $\mathrm{Fe}$ and $\mathrm{Co}$, which are difficult to recover;

5. Seawater samples that have suffered significant wall losses should not be analyzed for dissolved $\mathrm{Fe}$ or Co concentrations unless they have been acidified for at least 30 weeks, which is 1.5 times the maximum desorption timescale that we tested for dissolved $\mathrm{Fe}$ and $\mathrm{Co}$; 
6. If analyzing metals other than dissolved $\mathrm{Fe}$ and $\mathrm{Co}, 12$ weeks of acidification is sufficient for complete desorption of most metals, and analysis after shorter timescales is acceptable if samples were not left unacidified for very long.

Additionally, looking across the experiments, a few conclusions about natural marine colloidal metal size partitioning can also be made. First, the colloidal preservation experiment showed contrasting size partitioning and preservation behavior of metals collected from different locations (West Antarctic Peninsula vs. Galveston Bay), suggesting that the inherent differences in physicochemical speciation at different locations largely affect the kinetics of metal exchangeability in seawater. As noted above, this is particularly noticeable in the preservation of $\mathrm{dZn}$ size partitioning (Figure 4d), where a statistically significant aggregation into colloids in both the frozen and room temperature treatment was observed in the Southern Ocean bottom water, while there was no discernible change in the \% cZn over the same timescale in Galveston

582 Bay estuarine surface water. This pattern was also true for $\mathrm{Cu}$ and $\mathrm{Ni}$ (Figure $4 \mathrm{~b}$-c), indicative of a more stable equilibrium between the soluble and colloidal phases in Galveston Bay waters.

We also found that colloids tended to be more abundant in Galveston Bay, consistent with the literature [Guo and Santschi, 1997; Wen et al., 1999], suggesting a permanent sedimentary, riverine, or in situ flocculation source that maintains the presence of colloids at this estuarine site. The fact that metal preservation was so consistent in Galveston Bay, with little apparent wall loss or exchange, indicates that the ligands or other compounds involved in forming colloidal metals in Galveston Bay are very different from those in the Southern Ocean samples. The prior work of Wen et al. [1999] in the Galveston Bay estuary showed high \% colloids for $\mathrm{Fe}, \mathrm{Cu}, \mathrm{Zn}$, and $\mathrm{Pb}$ (55 to 91\%) as well as an average 55\% contribution of colloids to

592 the organic carbon phase into which many metal-binding ligands might fall. Wen et al. [1999]

593 further estimated that only $1 \%$ of the surface sites in the very abundant colloidal organic carbon

594 (COC) phase would be sufficient to complex all trace metals, which is supported by a strong 595 correlation between COC and colloidal Co, Ni, Cu, Zn, Cd. Wen et al. [1999] also report a large 596 contribution of freshwater colloids associated with both metal and organic carbon phases in 597 Galveston Bay, which is important as river water appears a major component of the Galveston 598 Bay water collected during this study (salinity 26.5). This contribution from rivers has been 599 shown to be a significant source of colloidal metals such as $\mathrm{Fe}, \mathrm{Ni}$ and $\mathrm{Cu}$ in particular (Powell 600 et al., 1996), which when combined with the increased colloidal complexation capacity observed 601 between COC and some metals, may be responsible for the different partitioning behaviors we 602 observed in our two preservation experiments.

603 Second, we may interpret the differences in colloidal behavior in the Southern Ocean vs. 604 Galveston Bay experiments as anecdotal evidence that cold seawater samples do not perform as 
605 well in the CFF system. As noted above, the temperature and salinity of a sample will have an 606 effect on the overall initial physicochemical speciation of the sample. For example, the Southern 607 Ocean metals other than Fe, in general, did not have well preserved size partitioning, while 608 Galveston Bay $\left(25^{\circ} \mathrm{C}\right.$ warmer and fresher) showed much better stability of size partitioning of 609 these same metals over time. Additionally, the frozen and then thawed samples showed relatively 610 poorer recovery in the Galveston Bay experiment, perhaps a function of having been stored at a 611 colder temperature. Previous studies have shown that frozen and thawed samples may increase 612 the solubility of Fe over time [Schlosser et al., 2011], which would have a direct effect on 613 speciation measurements and recovery.

614 Third, while it is common practice to freeze and thaw unacidified samples as a way of 615 preserving DOC concentrations [Fellman et al., 2008], ligand concentrations [Apte et al., 1990], 616 and even chemical speciation of trace metals when immediate analyses are not possible 617 [Capodaglio et al., 1995; Buck et al., 2012], there may actually be artifacts in physicochemical 618 speciation that arise simply from the freeze-thaw process itself. Previous studies have found that 619 some sampling and storage artifacts, such as bottle adsorption, are in fact increased under cold 620 conditions [Fitzsimmons and Boyle, 2012]. While we observed no change in dFe concentration 621 or size partitioning using frozen samples over 3 weeks in the Colloid Preservation Experiments, 622 we cannot rule out that the process of freezing and thawing may have some effect on the kinetics 623 of exchange between soluble and colloidal compounds in any seawater sample. This could 624 include the possibility of self-aggregation or self-assembly [Ding et al., 2008; Verdugo et al., 6252008 that may be a side effect of the freezing process or a natural function of these organic 626 colloids.

627 Fourth, the results of all of our experiments show that the kinetics of colloidal exchange 628 and metal adsorption are variable across different metals. Many factors contribute to this 629 variability, such as as the chemistry of the metal, the characteristics of the solution (in this case 630 unacidified seawater) including organic ligand concentrations, the properties of the container, 631 and other external factors such as temperature [Massee et al., 1981]. We can apply some of these 632 parameters directly to our study. For instance, adsorption to plastics such as polyethylene is 633 initially motivated by hydrophobic and/or van der Waal's attraction of metal complexes with the 634 hydrophobic plastic surface, perhaps encouraging greater adsorption of metals bound by organic 635 compounds with hydrophobic “tails." Indeed, metals like $\mathrm{Fe}, \mathrm{Co}, \mathrm{Zn}$, and $\mathrm{Cu}$, all of which are 636 organically complexed in seawater [Bruland et al., 2013], showed more significant (4-91\%) 637 adsorption in our experiments over 40 months and even 24 hours compared to metals commonly 638 found as free ions in seawater like Mn [Byrne, 2002]. However, experiments from decades ago 639 have shown that sustained cationic adsorption to plastic surfaces is a product of ion exchange 640 with hydroxide groups in the inner charged layer of polyethylene's double charged surface layer 
641 [Beneš and Smetana, 1969]. Thus, it is expected that hydrolyzed metals will adsorb more rapidly 642 compared to free ions [Starik et al., 1963; James and Healy, 1972b] [Starik et al., 1963; James

643 and Healy, 1972a], leading us to hypothesize that hydrolysable metals or metals with significant 644 organic complexation, like Fe, will show a greater loss to bottle walls over time. Addtionally, 645 organic complexation may indicate a proclivity to enter the colloidal phase [Dammshäuser and

646 Croot, 2012], as demonstrated for metals such as Fe where colloids are a significant component 647 of the dissolved phase [Fitzsimmons and Boyle, 2014a]. There is often more consistent

648 partitioning between soluble and colloidal phases for organically complexed metals such as $\mathrm{Ni}$ 649 and $\mathrm{Cu}$ across the global ocean (Jensen and Fitzsimmons, unpublished). Thus, any ingrowth of 650 colloids over 70 hours is significant. Likewise, metals such as Mn that typically exist largely or 651 entirely in the soluble phase showed no colloidal growth and were preserved for the dissolved 652 phase under frozen conditions.

653 Finally, very little work, to the authors' knowledge, has directly examined metal 654 desorption kinetics from sample bottle walls, although early studies stressed the importance of 655 acid cleaning sampling containers and materials before use to prevent desorption of metal 656 contaminants from bottle manufacture [Batley and Gardner, 1977; Ross, 1986]. It is well known 657 that protons significantly disrupt the binding of metals to common ligand groups [Doucet et al., 658 2007], making acidification commonplace in long-term sample storage. We found that while 659 adsorption was significant for Fe and Co over even 24 hours, desorption remained slow and 660 incomplete after 20 weeks. In contrast, $\mathrm{Cu}$ did not show significant adsorption, but also did not 661 completely desorb over the full 20 weeks. Therefore, we recommend preventing samples from 662 experiencing significant adsorption to bottle walls, since it can be hard to recover these metals 663 even after extended time acidified. In the event that bottle wall adsorption does occur, we 664 recommend allowing samples to sit acidified for at least 30 weeks in order to maximize the 665 probability of metal remobilization.

666

667 Conclusions

668 The accurate determination of trace metal concentrations and physicochemical speciation 669 in seawater has progressed over the last decades as clean sampling and storage procedures have 670 been increasingly optimized. However, there are still challenges and unanswered questions 671 regarding filtration and sample processing that warrant further examination, particularly in the 672 context of multi-elemental analyses. For instance, while ultrafiltration to determine the colloidal 673 concentrations of trace metals has received increased attention in the oceanographic literature 674 ([Guo and Santschi, 2007] and references therein), the timescale of storage prior to filtration and 675 the potential effects this has on measured size fractionation remain poorly known. Additionally, 676 important contributing factors to measuring dissolved and colloidal metal concentrations over 
677 time will include sampling and storage artifacts such as adsorption to bottle walls. Combining 678 these issues, this study sought to answer four major questions: 1) Can we preserve the size 679 partitioning of trace metals over time under frozen or room temperature conditions?, 2) Do 680 colloids "grow in" over time following removal, and if so, how fast?, 3) How fast do metals 681 adsorb to bottle walls in the absence of acidification?, and 4) Once samples are acidified, how 682 quickly do metals desorb from bottle walls? The results of these experiments allowed us to make 683 several recommendations involving sample storage and proposed timing of ultrafiltration and 684 analyses. For example, it is evident from the Colloid Preservation Experiment that only the size 685 partitioning of $\mathrm{Fe}$ (and perhaps labile $\mathrm{Co}$ ) can be preserved under frozen conditions. Notably, this 686 experiment also demonstrated that the natural physicochemical speciation of waters will give rise 687 to differential exchange between the soluble and colloidal phases and thus effect their ability to 688 be preserved.

689 In the Colloid Exchangeability Experiment, it was clear that in most cases metal colloids 690 (once removed) do grow back in via aggregation from the soluble phase, often exceeding the 691 initial colloidal fraction. Prior work suggested that metal-organic complexation in seawater may 692 impart a proclivity for trace metals to form colloids [Dammshäuser and Croot, 2012]. Thus it is 693 not surprising that $\mathrm{Fe}, \mathrm{Ni}, \mathrm{Cu}$ and $\mathrm{Zn}$, which are all thought to be organically complexed in 694 seawater, regenerated colloids in as short as 14 hours, whereas Mn, which is thought to exist 695 mostly as a free cation and weak chloride complexes in solution, did not aggregate into colloids.

696 It is difficult to conclude from this study why colloids might re-form and reach higher

697 proportions compared to their original natural partitioning, but future work might combine 698 chemical speciation measurements with these colloid re-aggregation kinetics to investigate the 699 mechanisms responsible for re-aggregation.

The results of the Bottle Adsorption and Desorption experiment simply add to what we already knew about adsorption kinetics of Fe, namely that the adsorption rate is dependent on both bottle material and surface-to-volume ratio It is evident that smaller bottles with higher $\mathrm{SA}: \mathrm{V}$ ratios promote more sorption, not just for $\mathrm{Fe}$, but also for $\mathrm{Co}, \mathrm{Ni}, \mathrm{Cu}$ and $\mathrm{Zn}$. We also saw less sorption using LPDE bottles compared to previous studies such as [Fischer et al., 2007; Schlosser et al., 2011; Fitzsimmons and Boyle, 2012] that used HDPE bottles. Even so, over 24 hours, dissolved $\mathrm{Fe}, \mathrm{Co}, \mathrm{Cu}$, and $\mathrm{Zn}$ all showed significant adsorption to LDPE bottle walls, demonstrating that any further sample processing, such as ultrafiltration, should occur as soon as possible after sample collection in order to avoid metal adsorption artifacts.

Based on the results of the desorption experiment we conclude that 20 weeks (5 months) 711 most susceptible to adsorption) from LDPE bottles. However, it is important to note that our 712 samples were stored unacidified for 22 months prior to acidification, which is much longer than 
713 most oceanographers wait to acidify after sample collection. It would be informative to conduct

714 experiments to learn whether storage time prior to acidification plays a role in setting the

715 desorption time scale. Finally, because we observed different behaviors and different kinetics for

716 different metals in different water types, our recommendations on how to avoid artifacts in trace

717 metal speciation measurements should be supplemented with further experimentation under

718 one's "local" conditions of water chemistry and temperature when sample processing and sample

719 acidification cannot be conducted as soon as possible after collection.

\section{Acknowledgements}

723 We would like to thank the Captain and crew of the USCGC Healy, the ARSV Gould, and the

724 R/V Trident; Dave Kadko, Greg Cutter, Hugh Ducklow, and Robert Sherrell for cruise

725 leadership and sampling opportunities; Gabi Weiss, Simone Moos, Amber Annett, Janelle

726 Steffen, and Nate Lanning for sample collection at sea and processing ashore; and Luz Romero

727 for assistance with ICP-MS analyses. This work was supported by NSF OCE 1434493 and

7281713677 to JNF, NSF OCE 1355833 to WML (Healy), a Texas A\&M T3 Triad to JNF (Trident),

729 and a Texas Sea Grant "Grants-In-Aid of Graduate Research" award 2018SP-S-Jensen-GIA

730 (Trident) to LTJ.

\section{Figure captions}

737 Table 1. Summary of SAFe D1, blank, and limit of detection (LOD) results from this study

738 compared to the May 2013 consensus values reported by GEOTRACES. All values are reported 739 in $\mathrm{nmol} / \mathrm{kg}$.

740 Figure 1. Schematic of the Colloid Preservation Experiment methods. All samples came from

741 the same, homogenized seawater sample (a single Niskin-X bottle in the Southern Ocean or a

742 carboy in Galveston Bay). Blue bottles indicate samples frozen at $-20^{\circ} \mathrm{C}$, while black bottles

743 indicate samples kept at room temperature in the dark. "Pour" indicates samples that were

744 directly poured from the corresponding $250 \mathrm{~mL}$ sample. "CFF" indicates when samples were

745 ultrafiltered to permeate $(\mathrm{P})$ or retentate $(\mathrm{R})$ solutions. The Southern Ocean experiment had three

746 timepoints: $\mathrm{T} 0, \mathrm{~T}=7$ days, $\mathrm{T}=21$ days, while the Galveston Bay experiment had four

747 timepoints: $\mathrm{T} 0, \mathrm{~T}=2$ days, $\mathrm{T}=9$ days, $\mathrm{T}=23$ days. 
748 Figure 2. Schematic of the Colloid Exchangeability Experiment methods. All samples came 749 from the same, original Niskin-X $12 \mathrm{~L}$ bottle. "Pour" indicates that samples were directly poured 750 from the corresponding $2 \mathrm{~L}$ sample. "CFF" indicates when samples were ultrafiltered to permeate 751 (P) or retentate $(\mathrm{R})$ solutions. All time points originated from the same, homogenized $2 \mathrm{~L}$

752 permeate sample, which had the colloids removed by ultrafiltration at $\mathrm{T}=0$.

753 Figure 3. Schematic of the Adsorption (left) and Desorption (right) Experiment methods. The 754 water for both was taken from the same depth but two separate GO-Flo bottles. The time points 755 for the Adsorption Experiment are in hours, except for the final time point of 40 months. Dark 756 blue bottles indicate transfer to new, acid-cleaned bottles. Red (outlined) bottles indicate 757 acidification. Note that the adsorption experiment was performed in triplicate while the 758 desorption experiment was performed in duplicate, both over two bottle sizes: $125 \mathrm{~mL}$ and 250 $759 \mathrm{~mL}$.

760 Figure 4. Summary of all results of the Colloid Preservation Experiment. The left hand and 761 right hand columns represent the initial Southern Ocean and subsequent Galveston Bay 762 experiments, respectively. The legend for all treatment types is included in panel (a), where 763 black is the initial seawater sample. The black line separates where the left-hand axes 764 (concentration) are applicable to the "Dissolved" and "Permeate" groups of data from where the 765 right-hand axes (percentage) are applicable to the "\% Colloids" and "\% Recovery" groups of data. The red error bars represent standard deviation over replicate bottles within a given time point. The frozen 9 day time point in the Galveston Bay experiment are removed for permeate concentration, $\%$ colloids and $\%$ recovery due to clear contamination of the permeate solution across all metal types. * indicates a result that is significantly different from the initial (T0) result, used a two-tailed heteroscedastic t-test $(p<0.05)$.

771 Figure 5. Summary of all results of the Colloid Exchangeability Experiment across all metals.

772 The legend for all treatment types is included in panel (a), where black bars are the initial

773 permeate solution concentration re-poured at each subsequent time point to monitor for wall loss

774 (compared to the white bar at T0, which is the initial permeate soluble metal concentration).

775 White bars at non-zero timepoints are the re-ultrafiltered soluble concentrations, and grey bars

776 are the re-ultrafiltered colloidal concentrations, obtained by subtracting the white bar from the

777 black bar. Overlaid in red is the \% colloidal metal (cMe/dFe; right axis) at each time point. The

778 T0 time point contains the initial size partitioning of the seawater sample, and the initial \%

779 colloids is indicated by the dashed red line. Panel E shows unpublished data for Fe from a

780 prototype of this experiment using water from $800 \mathrm{~m}$ depth at Station ALOHA, showing similar 781 trends for Fe across a comparable timescale.

782 Figure 6. Results from the Adsorption (left) and Desorption (right) Experiments. Water was 783 collected at $100 \mathrm{~m}$ depth in the Arctic Ocean and filtered immediately upon collection and stored 
784 in the dark at room temperature for 22 months. The grey bar indicates the average value of the initial dissolved metal concentration for the seawater used in these experiments, and the width reflects the standard deviation in those initial measurements. $125 \mathrm{~mL}$ sample treatments are shown as a closed circle, while $250 \mathrm{~mL}$ sample treatments are shown as an open circle. The annotations refer to the $\%$ change in concentration from the average initial dMe concentration (grey bar) at select time points. ${ }^{*}$ indicates a result that is statistically significant from the initial $(\mathrm{T}=0)$ adsorption result (grey bar), used a two-tailed heteroscedastic t-test $(p<0.05)$. Asterisk above the data is for $250 \mathrm{~mL}$ treatment and below is for the $125 \mathrm{~mL}$ treatment. $\mathrm{Pb}$ has been excluded to due poor experimental reproducibility.

\section{References}

Apte, S. C., M. J. Gardner, J. E. Ravenscroft, and J. A. Turrell (1990), Examination of the range of copper complexing ligands in natural waters using a combination of cathodic stripping voltammetry and computer simulation, Analytica Chimica Acta, 235, 287-297. Baalousha, M., B. Stolpe, and J. R. Lead (2011), Flow field-flow fractionation for the analysis and characterization of natural colloids and manufactured nanoparticles in environmental systems: A critical review, Journal of Chromatography A, 1218(27), 4078-4103.

Bartell, F. E., T. L. Thomas, and Y. Fu (1951), Thermodynamics of Adsorption from Solutions. IV. Temperature Dependence of Adsorption, The Journal of Physical Chemistry, 55(9), 1456-1462.

Baskaran, M., P. H. Santschi, G. Benoit, and B. D. Honeyman (1992), Scavenging of thorium isotopes by colloids in seawater of the Gulf of Mexico, Geochimica et Cosmochimica Acta, 56(9), 3375-3388.

Batley, G. E., and D. Gardner (1977), Sampling and storage of natural waters for trace metal analysis, Water Research, 11(9), 745-756.

Beneš, P., and J. Smetana (1969), Radiochemical study of the sorption of trace elements. IV. Adsorption of iron on polyethylene and its state in aqueous solutions, Collection of Czechoslovak Chemical Communications, 34(5), 1360-1374.

Benner, R., J. D. Pakulski, M. McCarthy, J. I. Hedges, and P. G. HATCHER (1992), Bulk Chemical Characteristics of Dissolved Organic Matter in the Ocean, Science, 255(5051), 1561-1564.

Bruland, K., R. Middag, and M. Lohan (2013), Controls of trace metals in seawater. Bruland, K. W. (1989), Complexation of zinc by natural organic ligands in the central North Pacific, Limnology and Oceanography, 34(2), 269-285.

Bruland, K. W., and E. L. Rue (2001), Iron: Analytical methods for the determination of concentrations and speciation, The Biogeochemistry of Iron in Seawater, 255-289. 
824 Buck, K. N., K. E. Selph, and K. A. Barbeau (2010), Iron-binding ligand production and 825 copper speciation in an incubation experiment of Antarctic Peninsula shelf waters from the 826 Bransfield Strait, Southern Ocean, Marine Chemistry, 122(1), 148-159.

827 Buck, K. N., J. Moffett, K. A. Barbeau, R. M. Bundy, Y. Kondo, and J. Wu (2012), The organic complexation of iron and copper: an intercomparison of competitive ligand exchange adsorptive cathodic stripping voltammetry (CLE - ACSV) techniques, Limnology and Oceanography: Methods, 10(7), 496-515.

832

833 Buesseler, K. O., et al. (1996), An intercomparison of cross-flow filtration techniques used for sampling marine colloids: Overview and organic carbon results, Marine Chemistry, 55(1), 1-31.

Buffle, J., D. Perret, and M. Newman (1992), The use of filtration and ultrafiltration for size fractionation of aquatic particles, colloids, and macromolecules, in Environmental particles. IUPAC series on environmental analytical and physical chemistry, edited by J. Buffle and H. P. Van Leeuwen, pp. 171-230, Lewis Publishers.

Byrne, R. H. (2002), Inorganic speciation of dissolved elements in seawater: the influence of $\mathrm{pH}$ on concentration ratios, Geochemical Transactions, 3(1), 11.

840 Capodaglio, G., G. Scarponi, G. Toscano, C. Barbante, and P. Cescon (1995), Speciation of

841 trace metals in seawater by anodic stripping voltammetry: critical analytical steps,

842 Fresenius' journal of analytical chemistry, 351(4-5), 386-392.

843 Chen, M., and W.-X. Wang (2001), Bioavailability of natural colloid-bound iron to marine 844 plankton: Influences of colloidal size and aging, Limnology and Oceanography, 46(8), 19568451967. Chen, M., W.-X. Wang, and L. Guo (2004), Phase partitioning and solubility of iron in natural seawater controlled by dissolved organic matter, Global Biogeochemical Cycles, 18(4). Chen, M., R. C. H. Dei, W.-X. Wang, and L. Guo (2003), Marine diatom uptake of iron bound with natural colloids of different origins, Marine Chemistry, 81(3-4), 177-189.

851

852

853 Chin, W.-C., M. V. Orellana, and P. Verdugo (1998), Spontaneous assembly of marine dissolved organic matter into polymer gels, Nature, 391(6667), 568-572. Cuculić, V., and M. Branica (1996), Adsorption of trace metals from sea-water onto solid surfaces: analysis by anodic stripping voltammetry, Analyst, 121(8), 1127-1131. Cutter, G., P. Andersson, L. Codispoti, P. Croot, R. Francois, M. Lohan, H. Obata, and M. Rutgers vd Loeff (2010), Sampling and sample-handling protocols for GEOTRACES cruises, edited, GEOTRACES.

Dammshäuser, A., and P. L. Croot (2012), Low colloidal associations of aluminium and titanium in surface waters of the tropical Atlantic, Geochimica et Cosmochimica Acta, 96, 304-318.

860 Ding, Y.-X., W.-C. Chin, A. Rodriguez, C.-C. Hung, P. H. Santschi, and P. Verdugo (2008), Amphiphilic exopolymers from Sagittula stellata induce DOM self-assembly and formation of marine microgels, Marine Chemistry, 112(1), 11-19.

863

864

865 Doucet, F. J., J. R. Lead, and P. H. Santschi (2007), Colloid-trace element interactions in aquatic systems, IUPAC SERIES ON ANALYTICAL AND PHYSICAL CHEMISTRY OF ENVIRONMENTAL SYSTEMS, 10, 95. Erickson, H. P. (2009), Size and Shape of Protein Molecules at the Nanometer Level Determined by Sedimentation, Gel Filtration, and Electron Microscopy, Biological Procedures Online, 11(1), 32. 
Fellman, J. B., D. V. D'Amore, and E. Hood (2008), An evaluation of freezing as a preservation technique for analyzing dissolved organic $\mathrm{C}, \mathrm{N}$ and $\mathrm{P}$ in surface water samples, Science of The Total Environment, 392(2), 305-312.

872 Fischer, A. C., J. J. Kroon, T. G. Verburg, T. Teunissen, and H. T. Wolterbeek (2007), On the relevance of iron adsorption to container materials in small-volume experiments on iron marine chemistry: 55Fe-aided assessment of capacity, affinity and kinetics, Marine Chemistry, 107(4), 533-546. Fitzsimmons, J. N., and E. A. Boyle (2012), An intercalibration between the GEOTRACES GOFLO and the MITESS/Vanes sampling systems for dissolved iron concentration analyses (and a closer look at adsorption effects), Limnology and Oceanography: Methods, 10(6), 437-450.

Fitzsimmons, J. N., and E. A. Boyle (2014a), Both soluble and colloidal iron phases control dissolved iron variability in the tropical North Atlantic Ocean, Geochimica et Cosmochimica Acta, 125, 539-550.

883

884 Fitzsimmons, J. N., and E. A. Boyle (2014b), Assessment and comparison of Anopore and cross flow filtration methods for the determination of dissolved iron size fractionation into soluble and colloidal phases in seawater, Limnol. Oceanogr. Methods, 12, 246-263. Fitzsimmons, J. N., C. T. Hayes, S. N. Al-Subiai, R. Zhang, P. L. Morton, R. E. Weisend, F. Ascani, and E. A. Boyle (2015a), Daily to decadal variability of size-fractionated iron and iron-binding ligands at the Hawaii Ocean Time-series Station ALOHA, Geochimica et 889 Cosmochimica Acta, 171, 303-324. Fitzsimmons, J. N., G. G. Carrasco, J. Wu, S. Roshan, M. Hatta, C. I. Measures, T. M. Conway, S. G. John, and E. A. Boyle (2015b), Partitioning of dissolved iron and iron isotopes into soluble and colloidal phases along the GA03 GEOTRACES North Atlantic Transect, Deep-Sea Research Part II: Topical Studies in Oceanography, 116, 130-151.

894 Gaffney, J. S., N. A. Marley, and S. B. Clark (1996), Humic and fulvic acids: isolation, structure, and environmental role.

Gerringa, L. J. A., S. Blain, P. Laan, G. Sarthou, M. J. W. Veldhuis, C. P. D. Brussaard, E. Viollier, and K. R. Timmermans (2008), Fe-binding dissolved organic ligands near the Kerguelen Archipelago in the Southern Ocean (Indian sector), Deep Sea Research Part II: Topical Studies in Oceanography, 55(5), 606-621. Guo, L., and P. H. Santschi (1997), Composition and cycling of colloids in marine environments, Reviews of Geophysics, 35(1), 17-40.

\section{Guo, L., and P. H. Santschi (2007), Ultrafiltration and its Applications to Sampling and} Characterisation of Aquatic Colloids, in Environmental Colloids and Particles, edited by J. Buffle, H. P. Van Leuween, K. J. Wilkinson and J. R. Lead.

Hassler, C. S., V. Schoemann, C. M. Nichols, E. C. V. Butler, and P. W. Boyd (2011), Saccharides enhance iron bioavailability to Southern Ocean phytoplankton, Proceedings of the National Academy of Sciences, 108(3), 1076-1081.

Honeyman, B., and P. Santschi (1989), A Brownian-pumping model for oceanic trace metal scavenging: evidence from Th isotopes, Journal of Marine Research, 47(4), 951-992. Honeyman, B. D., and P. H. Santschi (1988), Metals in aquatic systems, Environmental Science \& Technology, 22(8), 862-871. Ingri, J., S. Nordling, J. Larsson, J. Rönnegård, N. Nilsson, I. Rodushkin, R. Dahlqvist, P. Andersson, and Ö. Gustafsson (2004), Size distribution of colloidal trace metals and organic carbon during a coastal bloom in the Baltic Sea, Marine Chemistry, 91(1), 117-130. 
915

916

917

918

919

920

921

922

923

924

925

926

927

928

929

930

931

932

933

934

935

936

937

938

939

940

941

942

943

944

945

946

947

948

949

950

951

952

953

954

955

956

957

958

James, R. O., and T. W. Healy (1972a), Adsorption of hydrolyzable metal ions at the oxidewater interface. I. Co(II) adsorption on $\mathrm{SiO} 2$ and $\mathrm{TiO} 2$ as model systems, Journal of Colloid and Interface Science, 40(1), 42-52.

James, R. O., and T. W. Healy (1972b), Adsorption of hydrolyzable metal ions at the oxidewater interface. III. A thermodynamic model of adsorption, Journal of Colloid and Interface Science, 40(1), 65-81.

Jensen, L. T., N. J. Wyatt, B. S. Twining, S. Rauschenberg, W. M. Landing, R. M. Sherrell, and J. N. Fitzsimmons Biogeochemical cycling of dissolved zinc in the Western Arctic (Arctic GEOTRACES GN01), Global Biogeochemical Cycles, O(ja).

Lagerström, M. E., M. P. Field, M. Séguret, L. Fischer, S. Hann, and R. M. Sherrell (2013), Automated on-line flow-injection ICP-MS determination of trace metals $(\mathrm{Mn}, \mathrm{Fe}, \mathrm{Co}, \mathrm{Ni}, \mathrm{Cu}$ and $\mathrm{Zn}$ ) in open ocean seawater: Application to the GEOTRACES program, Marine Chemistry, 155(0), 71-80.

Larsson, J., Ö. Gustafsson, and J. Ingri (2002), Evaluation and Optimization of Two Complementary Cross-Flow Ultrafiltration Systems toward Isolation of Coastal Surface Water Colloids, Environmental Science \& Technology, 36(10), 2236-2241.

Lohan, M. C., A. M. Aguilar-Islas, R. P. Franks, and K. W. Bruland (2005), Determination of iron and copper in seawater at pH 1.7 with a new commercially available chelating resin, NTA Superflow, Analytica Chimica Acta, 530(1), 121-129.

Louchouarn, P., S. Opsahl, and R. Benner (2000), Isolation and quantification of dissolved lignin from natural waters using solid-phase extraction and GC/MS, Analytical Chemistry, 72(13), 2780-2787.

Massee, R., F. J. M. J. Maessen, and J. J. M. De goeij (1981), Losses of silver, arsenic, cadmium, selenium and zinc traces from distilled water and artificial sea-water by sorption on various container surfaces, Analytica Chimica Acta, 127, 181-193.

Minor, E., J.-P. Simjouw, J. Boon, A. Kerkhoff, and J. Van der Horst (2002), Estuarine/marine UDOM as characterized by size-exclusion chromatography and organic mass spectrometry, Marine Chemistry, 78(2-3), 75-102.

Moffett, J. W., and C. Dupont (2007), Cu complexation by organic ligands in the sub-arctic NW Pacific and Bering Sea, Deep Sea Research Part I: Oceanographic Research Papers, 54(4), 586-595.

Oldham, V. E., A. Mucci, B. M. Tebo, and G. W. Luther Iii (2017), Soluble Mn(III)-L complexes are abundant in oxygenated waters and stabilized by humic ligands, Geochimica et Cosmochimica Acta, 199, 238-246.

Opsahl, S., and R. Benner (1997), Distribution and cycling of terrigenous dissolved organic matter in the ocean, Nature, 386(6624), 480-482.

Pellenbarg, R. E., and T. M. Church (1978), Storage and processing of estuarine water samples for trace metal analysis by atomic absorption spectrometry, Analytica Chimica Acta, 97(1), 81-86.

Powell, R. T., W. M. Landing, and J. E. Bauer (1996), Colloidal trace metals, organic carbon and nitrogen in a southeastern US estuary, Marine Chemistry, 55(1-2), 165-176.

Reitmeyer, R., R. T. Powell, W. M. Landing, and C. I. Measures (1996), Colloidal aluminum and iron in seawater: An intercomparison between various cross-flow ultrafiltration systems, Marine Chemistry, 55(1-2), 75-91. 
Roberts, D. R., R. G. Ford, and D. L. Sparks (2003), Kinetics and mechanisms of Zn complexation on metal oxides using EXAFS spectroscopy, Journal of Colloid and Interface

961 Science, 263(2), 364-376.

962 Ron, E. Z., and E. Rosenberg (2001), Natural roles of biosurfactants: Minireview, Environmental microbiology, 3(4), 229-236. Ross, H. B. (1986), The importance of reducing sample contamination in routine monitoring of trace metals in atmospheric precipitation, Atmospheric Environment (1967), 20(2), 401-405.

Rue, E. L., and K. W. Bruland (1995), Complexation of iron (III) by natural organic ligands in the Central North Pacific as determined by a new competitive ligand equilibration/adsorptive cathodic stripping voltammetric method, Marine chemistry, 50(14), 117-138.

Santschi, P. H. (2018), Marine colloids, agents of the self-cleansing capacity of aquatic systems: Historical perspective and new discoveries, Marine Chemistry, 207, 124-135. Santschi, P. H., L. Guo, M. Baskaran, S. Trumbore, J. Southon, T. S. Bianchi, B. Honeyman, and L. Cifuentes (1995), Isotopic evidence for the contemporary origin of high-molecular weight organic matter in oceanic environments, Geochimica et Cosmochimica Acta, 59(3), 625-631.

Scheinost, A. C., S. Abend, K. I. Pandya, and D. L. Sparks (2001), Kinetic controls on Cu and $\mathrm{Pb}$ sorption by ferrihydrite, Environmental Science \& Technology, 35(6), 1090-1096. Schlosser, C., and P. L. Croot (2008), Application of cross - flow filtration for determining the solubility of iron species in open ocean seawater, Limnology and Oceanography: Methods, 6(11), 630-642.

Schlosser, C., C. L. De La Rocha, and P. L. Croot (2011), Effects of iron surface adsorption and sample handling on iron solubility measurements, Marine Chemistry, 127(1), 48-55. Schlosser, C., P. Streu, and P. L. Croot (2013), Vivaspin ultrafiltration: A new approach for high resolution measurements of colloidal and soluble iron species, Limnology and Oceanography: Methods, 11(4), 187-201.

Schlosser, C., C. L. De La Rocha, P. Streu, and P. L. Croot (2012), Solubility of iron in the Southern Ocean, Limnology and Oceanography, 57(3), 684-697.

Sherrell, R. M., A. L. Annett, J. N. Fitzsimmons, V. J. Roccanova, and M. P. Meredith (2018), A "shallow bathtub ring" of local sedimentary iron input maintains the Palmer Deep biological hotspot on the West Antarctic Peninsula shelf, Philosophical Transactions of the Royal Society A: Mathematical, Physical and Engineering Sciences, 376(2122), 20170171. Sohrin, Y., S. Urushihara, S. Nakatsuka, T. Kono, E. Higo, T. Minami, K. Norisuye, and S. Umetani (2008), Multielemental Determination of GEOTRACES Key Trace Metals in Seawater by ICPMS after Preconcentration Using an Ethylenediaminetriacetic Acid Chelating Resin, Analytical Chemistry, 80(16), 6267-6273.

Starik, I., V. Scebetkobskij, and I. Skulskij (1963), The absorption of radioactive isotopes on polymer adsorbents that are not ion-exchangers III, Radiokhimiya, 4, 393-398. Stolpe, B., L. Guo, A. M. Shiller, and M. Hassellöv (2010), Size and composition of colloidal organic matter and trace elements in the Mississippi River, Pearl River and the northern 1002 Gulf of Mexico, as characterized by flow field-flow fractionation, Marine Chemistry, 118(3), 119-128. 
1003 Thuróczy, C.-E., A.-C. Alderkamp, P. Laan, L. J. A. Gerringa, M. M. Mills, G. L. Van Dijken, H. J. 1004 W. De Baar, and K. R. Arrigo (2012), Key role of organic complexation of iron in sustaining 1005 phytoplankton blooms in the Pine Island and Amundsen Polynyas (Southern Ocean), Deep 1006 Sea Research Part II: Topical Studies in Oceanography, 71-76, 49-60.

1007 Van den Berg, C., and M. Nimmo (1987), Determination of interactions of nickel with 1008 dissolved organic material in seawater using cathodic stripping voltammetry, Science of the 1009 Total Environment, 60, 185-195.

1010 Verdugo, P., M. V. Orellana, W.-C. Chin, T. W. Petersen, G. van den Eng, R. Benner, and J. I. 1011 Hedges (2008), Marine biopolymer self-assembly: implications for carbon cycling in the 1012 ocean, Faraday Discussions, 139(0), 393-398.

1013 von der Heyden, B. P., and A. N. Roychoudhury (2015), A review of colloidal iron 1014 partitioning and distribution in the open ocean, Marine Chemistry, 177, 9-19.

1015 Wells, M. L. (2002), Marine colloids and trace metals, Biogeochemistry of marine dissolved 1016 organic matter, 367-404.

1017 Wen, L.-S., P. H. Santschi, and D. Tang (1997), Interactions between radioactively labeled 1018 colloids and natural particles: Evidence for colloidal pumping, Geochimica et Cosmochimica 1019 Acta, 61(14), 2867-2878.

1020 Wen, L.-S., K. W. Warnken, and P. H. Santschi (2008), The role of organic carbon, iron, and 1021 aluminium oxyhydroxides as trace metal carriers: Comparison between the Trinity River 1022 and the Trinity River Estuary (Galveston Bay, Texas), Marine Chemistry, 112(1), 20-37. 1023 Wen, L.-S., P. Santschi, G. Gill, and C. Paternostro (1999), Estuarine trace metal distributions 1024 in Galveston Bay: importance of colloidal forms in the speciation of the dissolved phase, 1025 Marine Chemistry, 63(3-4), 185-212.

1026 Wen, L.-S., M. C. Stordal, D. Tang, G. A. Gill, and P. H. Santschi (1996), An ultraclean cross1027 flow ultrafiltration technique for the study of trace metal phase speciation in seawater, 1028 Marine Chemistry, 55(1), 129-152.

1029 Wilkinson, K. J., J. C. Negre, and J. Buffle (1997), Coagulation of colloidal material in surface 1030 waters: the role of natural organic matter, Journal of Contaminant Hydrology, 26(1), 2291031243.

1032 Wu, J., and G. W. Luther III (1995), Complexation of Fe (III) by natural organic ligands in the 1033 Northwest Atlantic Ocean by a competitive ligand equilibration method and a kinetic 1034 approach, Marine Chemistry, 50(1-4), 159-177. 


\begin{tabular}{|c|c|c|c|c|c|c|c|c|}
\hline Parameter & $\mathbf{d F e}$ & $\mathbf{d Z n}$ & $\mathbf{d N i}$ & $\mathbf{d C u}$ & $\mathbf{d C d}$ & $\mathbf{d P b}$ & $\mathbf{d M n}$ & $\mathbf{d C o}$ \\
\hline SAFe D1 mean & 0.604 & 7.395 & 8.584 & 2.087 & 1.045 & 0.023 & 0.409 & 0.032 \\
\hline Stdev & 0.063 & 0.212 & 0.098 & 0.063 & 0.006 & 0.003 & 0.009 & 0.001 \\
\hline $\mathrm{n}$ & 8 & 10 & 10 & 10 & 10 & 10 & 9 & 8 \\
\hline Consensus & 0.670 & 7.400 & 8.580 & 2.270 & 0.991 & 0.0277 & 0.35 & 0.045 \\
\hline $\begin{array}{c}\text { Consensus } \\
\text { stdev }\end{array}$ & 0.040 & 0.350 & 0.260 & 0.110 & 0.031 & 0.0026 & 0.05 & 0.005 \\
\hline Mean blank & 0.056 & 0.069 & 0.014 & 0.008 & 0.0003 & 0.0002 & 0.002 & 0.0004 \\
\hline Blank stdev & 0.010 & 0.011 & 0.003 & 0.003 & 0.0001 & 0.00004 & 0.001 & 0.0002 \\
\hline LOD & 0.031 & 0.033 & 0.010 & 0.008 & 0.0002 & 0.00012 & 0.002 & 0.0005 \\
\hline $\mathrm{n}$ & 4 & 4 & 4 & 4 & 4 & 4 & 4 & 4 \\
\hline
\end{tabular}




\section{Colloid Preservation Experiment}

Filtered SW sample $(0.2 \mu \mathrm{m})$

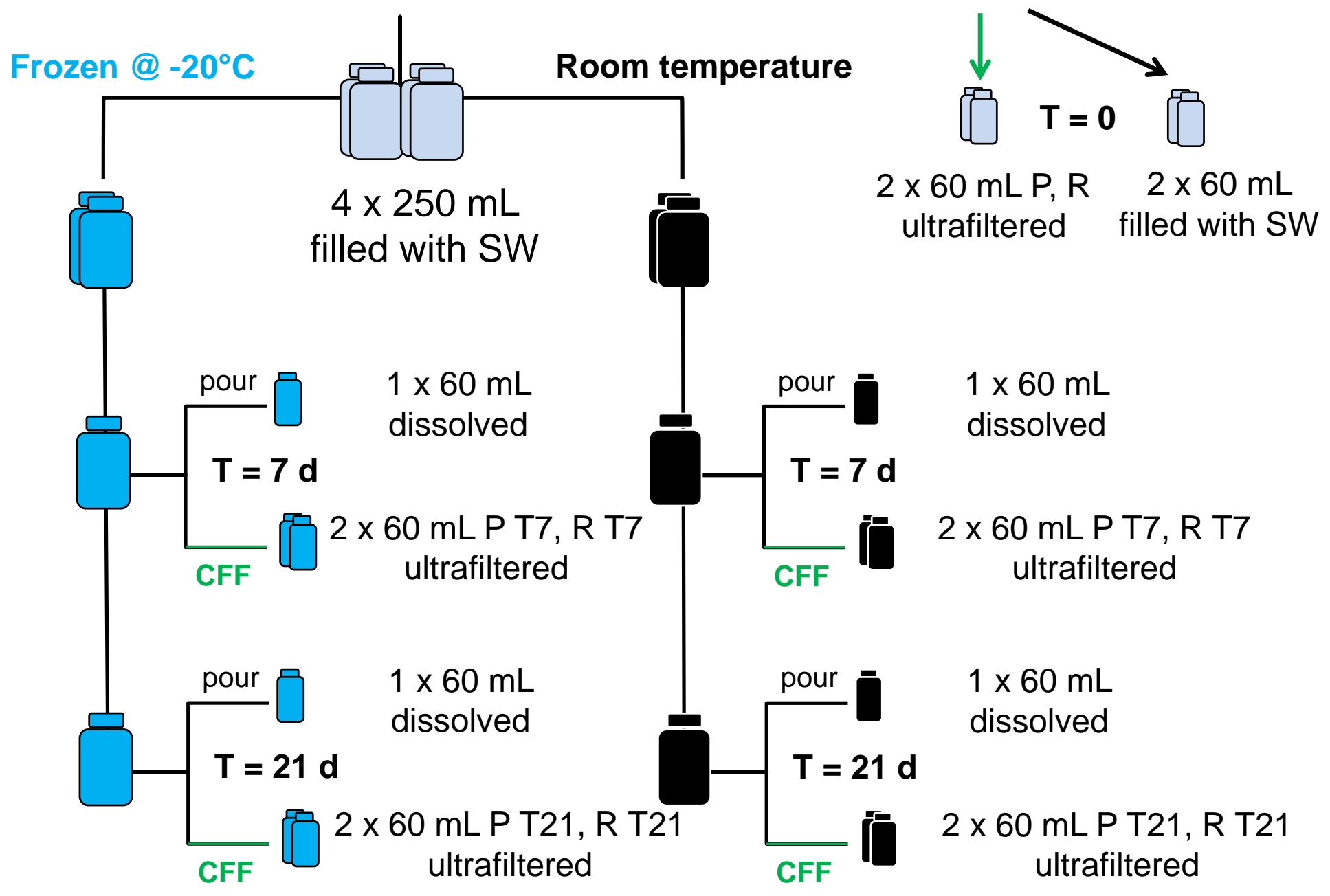




\section{Colloid Exchangeability Experiment}

1 Niskin-X filtered SW sample $(0.2 \mu \mathrm{m})$
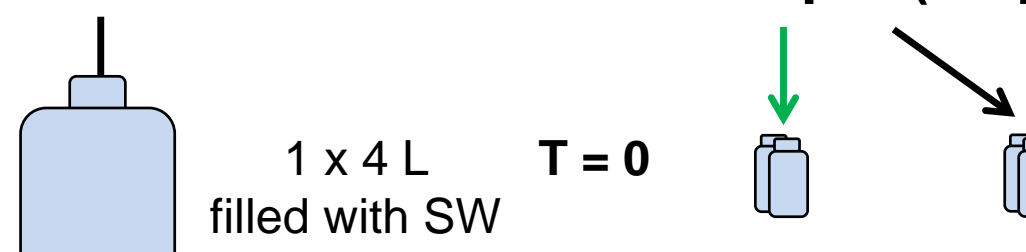

filled with SW

$2 \times 60 \mathrm{~mL} P, \mathrm{R}$ ultrafiltered

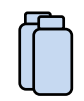

Colloids removed by CFF

$1 \times 2$ L Permeate

ultrafiltered

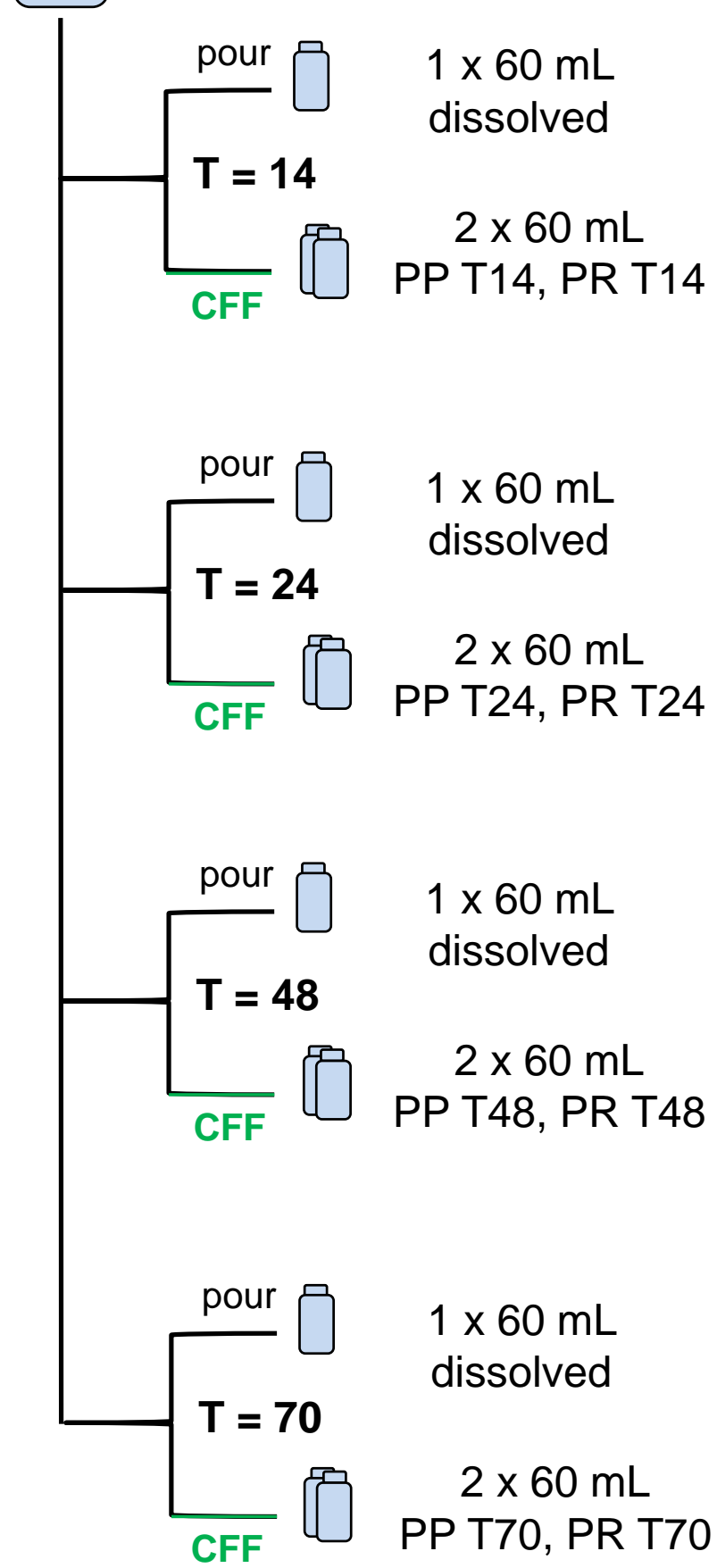




\section{Bottle Adsorption/Desorption Experiment}

\section{$10 \mathrm{~L}$ filtered $\mathrm{SW}$ sample $(0.2 \mu \mathrm{m})$}

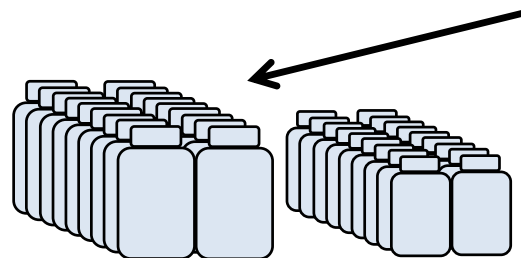

$18 \times 250 \mathrm{~mL}$ filled with SW

$18 \times 125 \mathrm{~mL}$ filled with SW

T0

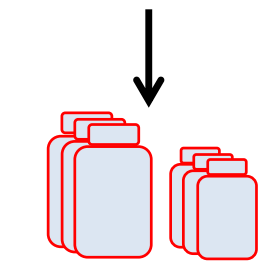

$3 \times 250 \mathrm{~mL}$

$3 \times 125 \mathrm{~mL}$

Acidified in original bottle

$3 \times 250 \mathrm{~mL}$

$3 \times 125 \mathrm{~mL}$

Transfer to new clean bottles

Acidified

$3 \times 250 \mathrm{~mL}$

$3 \times 125 \mathrm{~mL}$

Transfer to new clean bottles

Acidified

$3 \times 250 \mathrm{~mL}$

$3 \times 125 \mathrm{~mL}$

Transfer to new clean bottles

Acidified

$3 \times 250 \mathrm{~mL}$

$3 \times 125 \mathrm{~mL}$

Transfer to new clean bottles Acidified

$3 \times 250 \mathrm{~mL}$

$3 \times 125 \mathrm{~mL}$

Transfer to new clean bottles Acidified
$12 \times 250 \mathrm{~mL}$

$12 \times 125 \mathrm{~mL}$

Acidified in original bottle

$2 \times 250 \mathrm{~mL}$

$2 \times 125 \mathrm{~mL}$

$12 \times 250 \mathrm{~mL}$ filled with SW

$12 \times 125 \mathrm{~mL}$ filled with SW

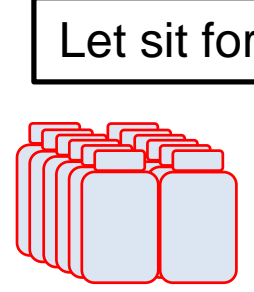

T0

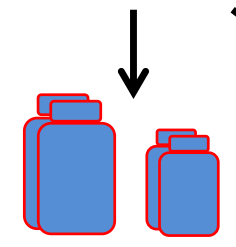

Transfer to new clean bottles

\section{$\mathrm{T}=1$ week}

$2 \times 250 \mathrm{~mL}$

$2 \times 125 \mathrm{~mL}$

Transfer to new clean bottles

\section{$\mathbf{T}=3$ weeks}

$2 \times 250 \mathrm{~mL}$

$2 \times 125 \mathrm{~mL}$

Transfer to new clean bottles

\section{$\mathrm{T}=7.5$ weeks}

$2 \times 250 \mathrm{~mL}$

$2 \times 125 \mathrm{~mL}$

Transfer to new clean bottles

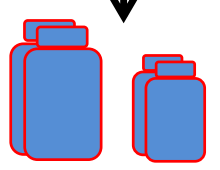

\section{$\mathrm{T}=12$ weeks}

$2 \times 250 \mathrm{~mL}$

$2 \times 125 \mathrm{~mL}$

Transfer to new clean bottles

$$
\mathrm{T}=20 \text { weeks }
$$

$2 \times 250 \mathrm{~mL}$

$2 \times 125 \mathrm{~mL}$

Transfer to new clean bottles 
Figure 4

a.

a. 2.5

Southern Ocean

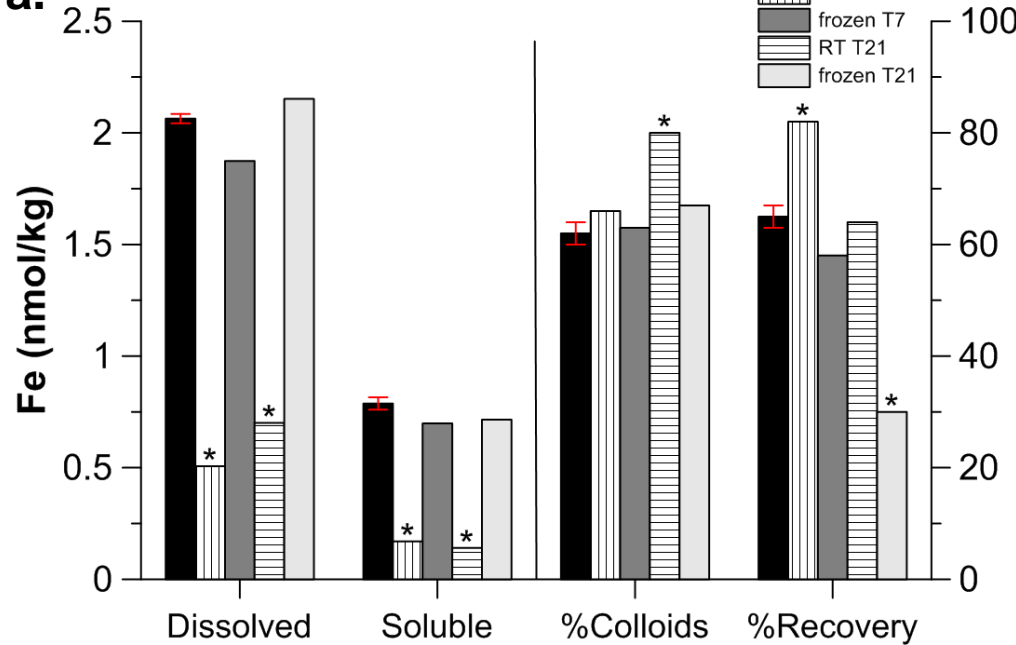

b.

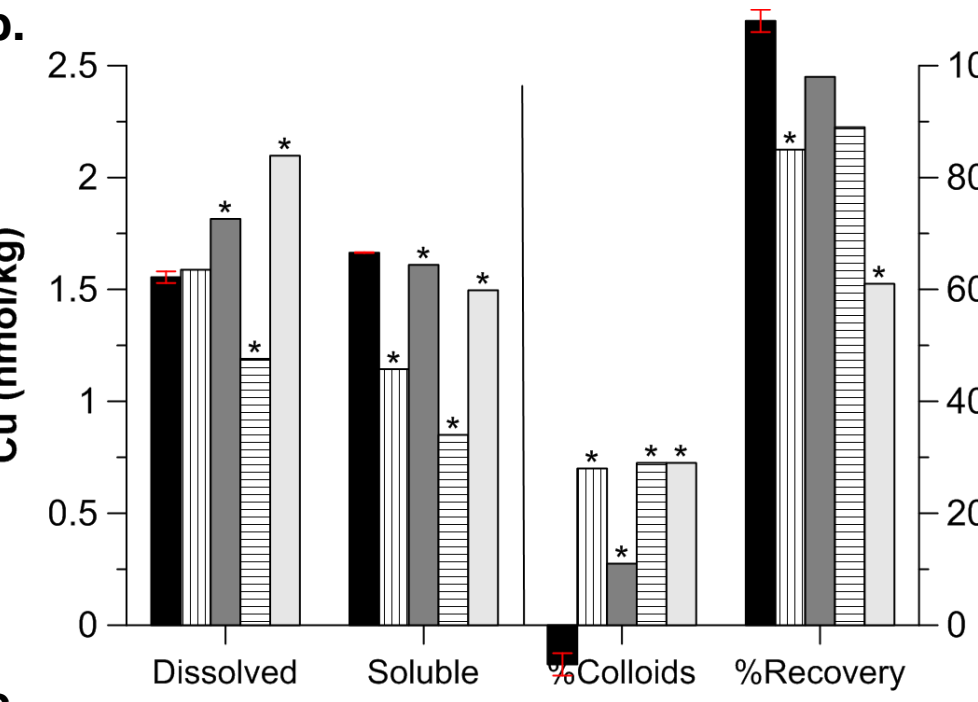

C.
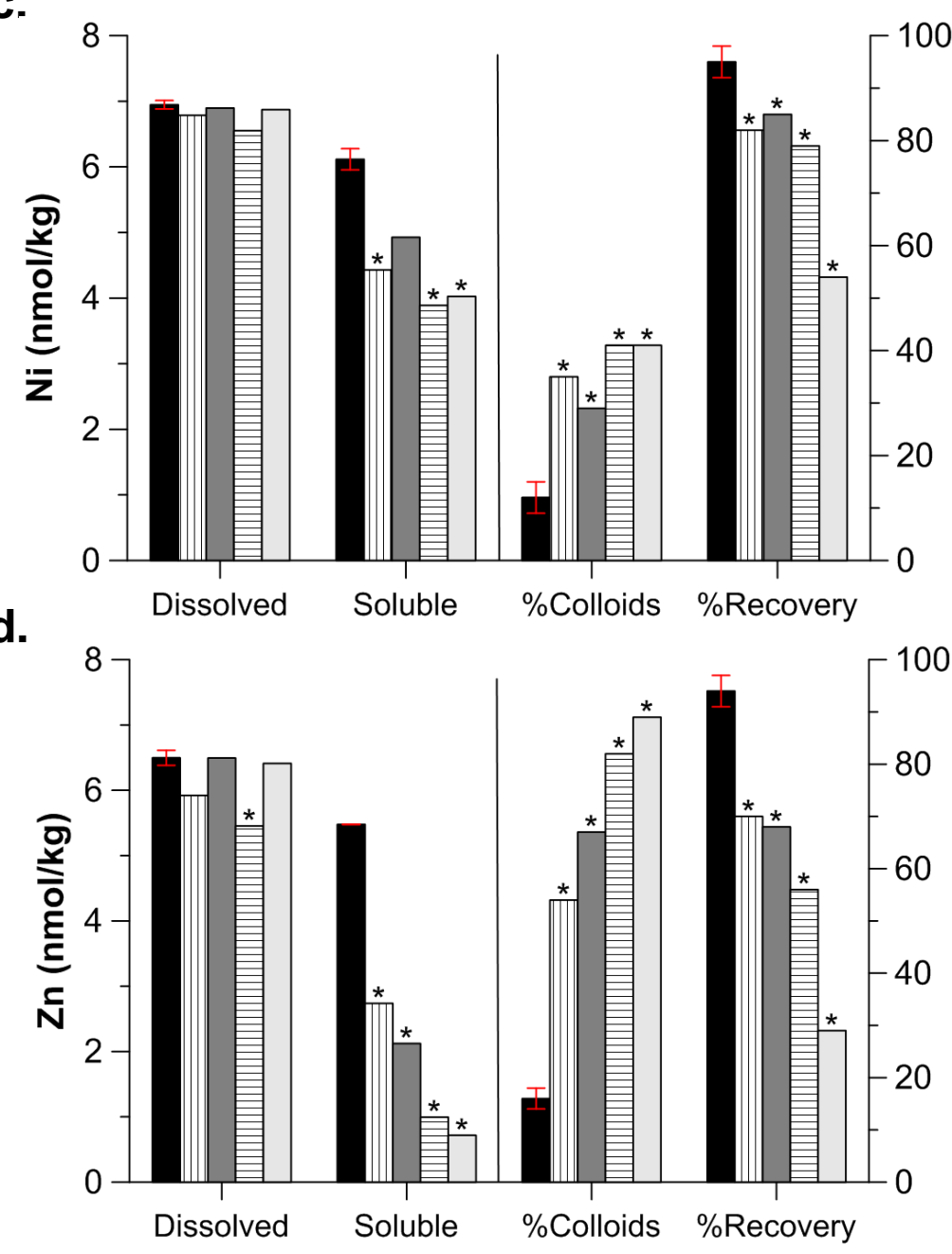

Galveston Bay

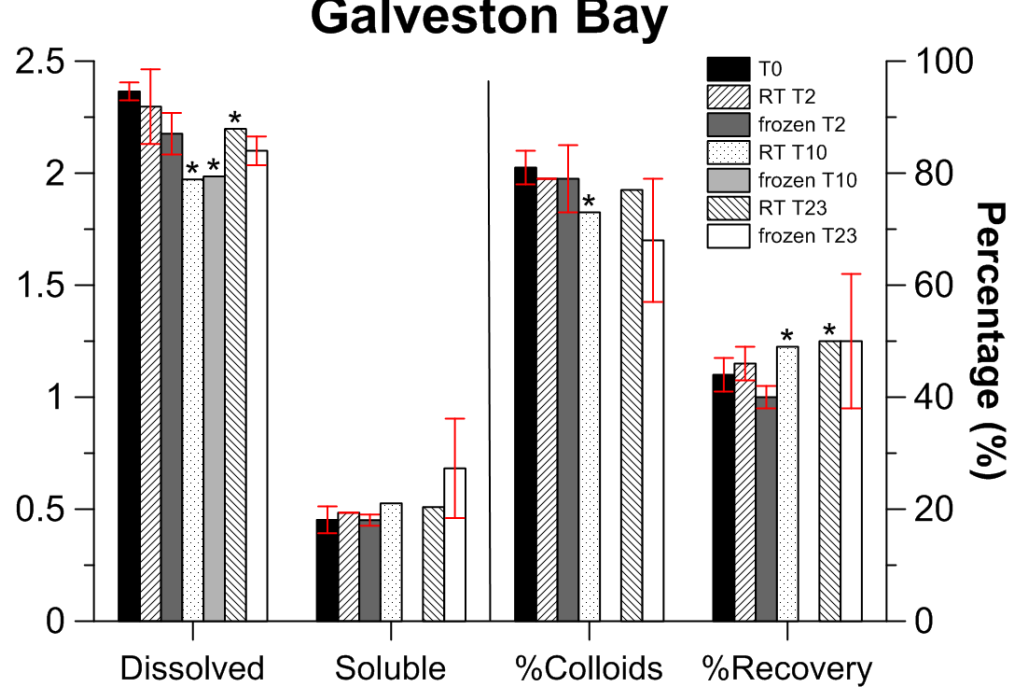

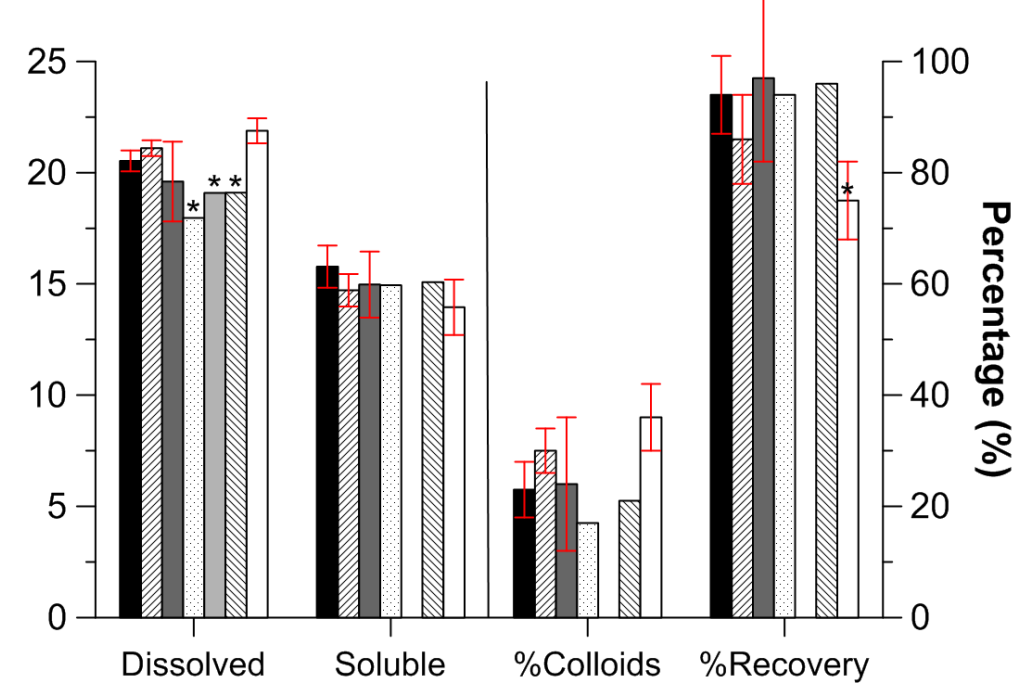

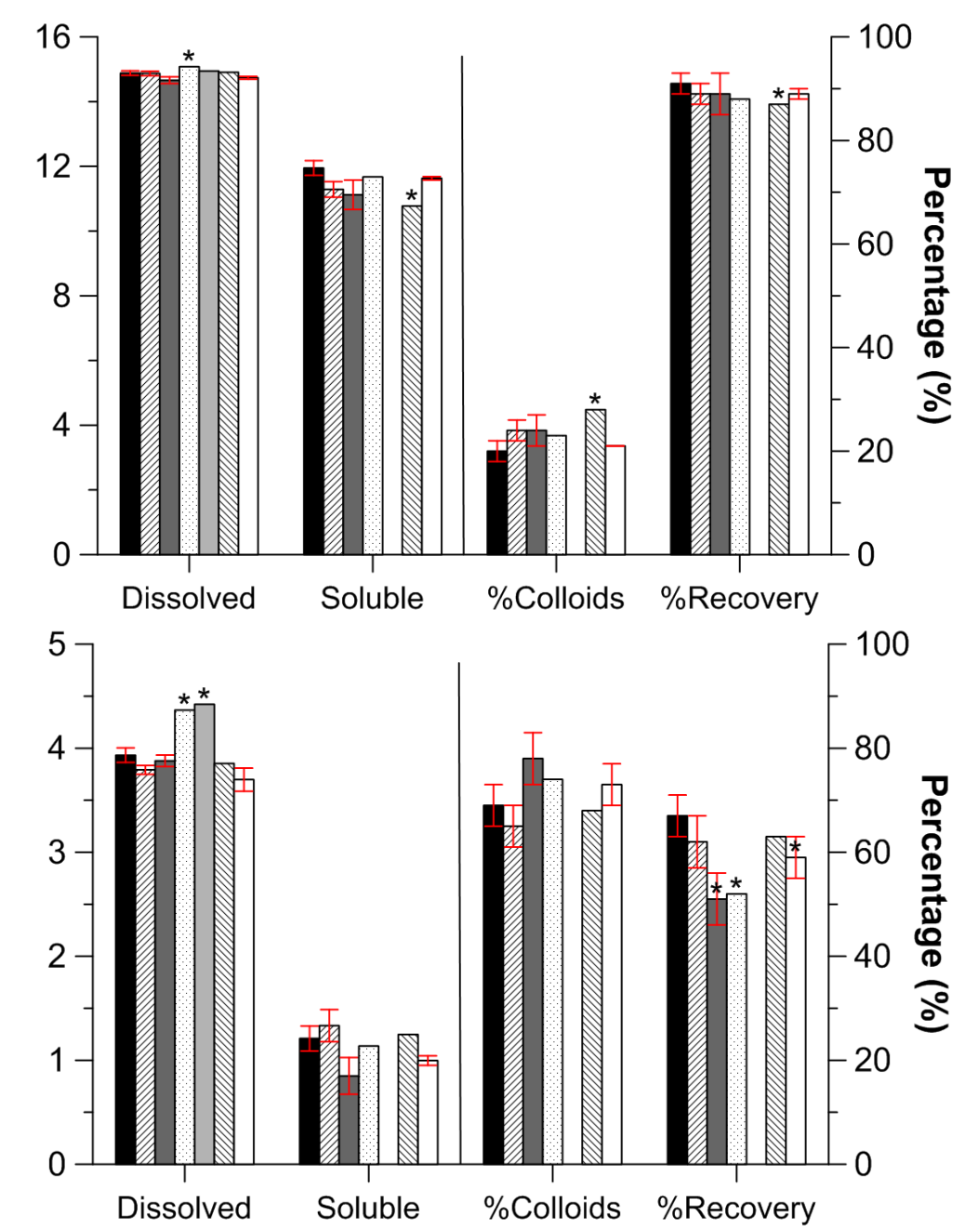


e. Southern Ocean

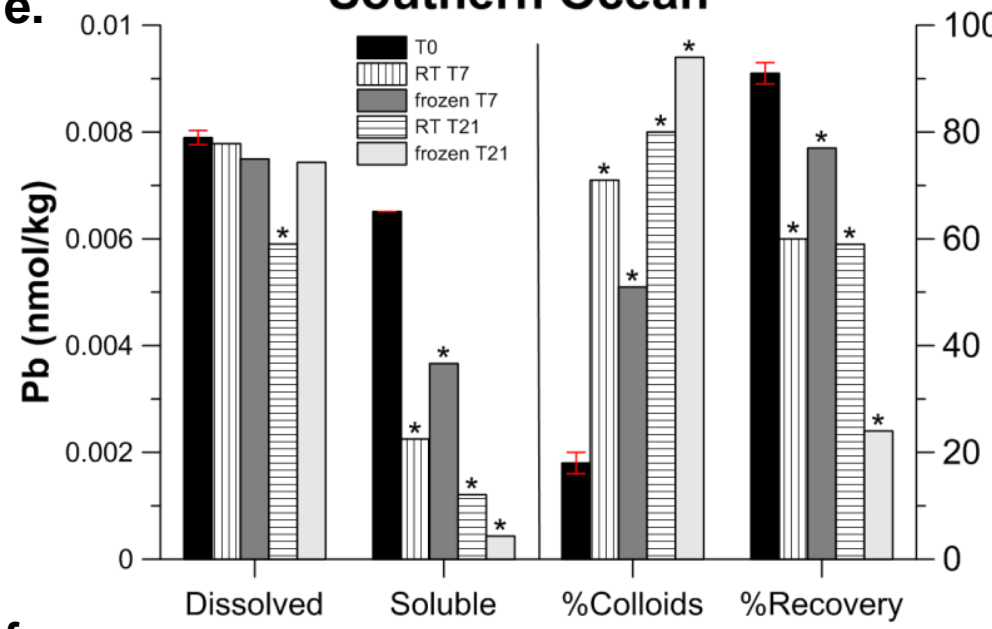

f.

g

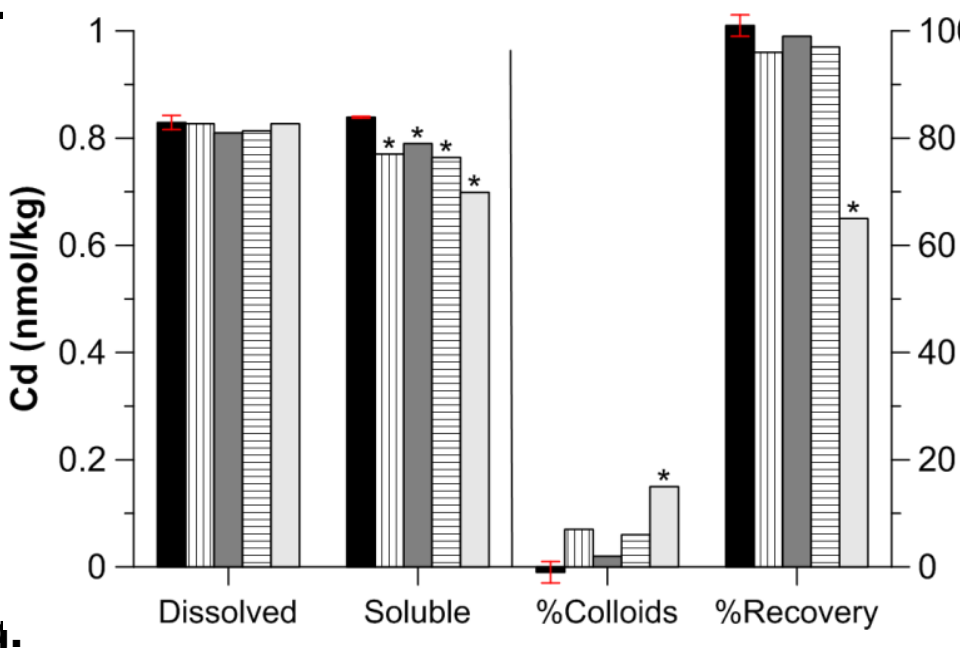

,

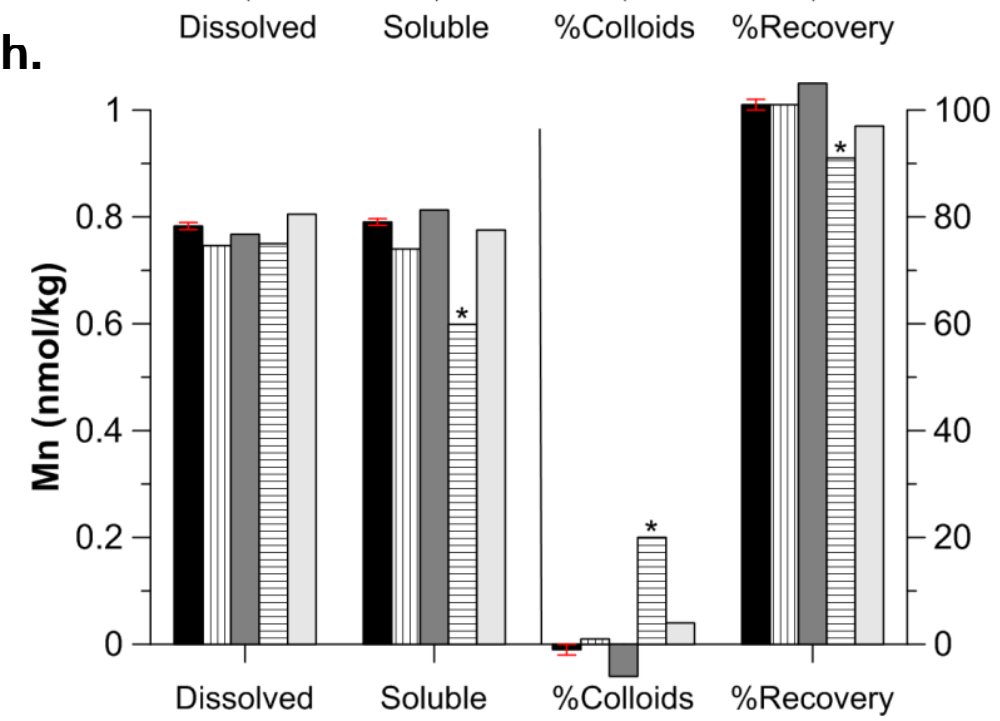

Galveston Bay
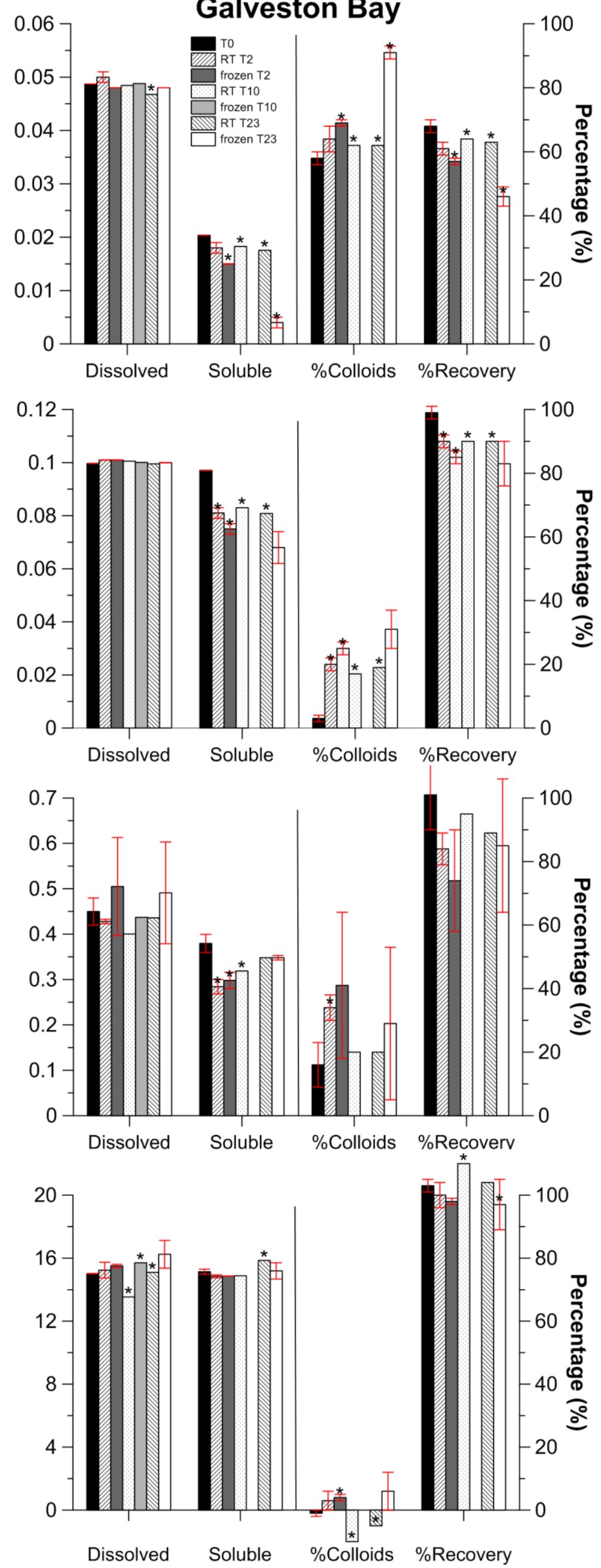
Figure 5

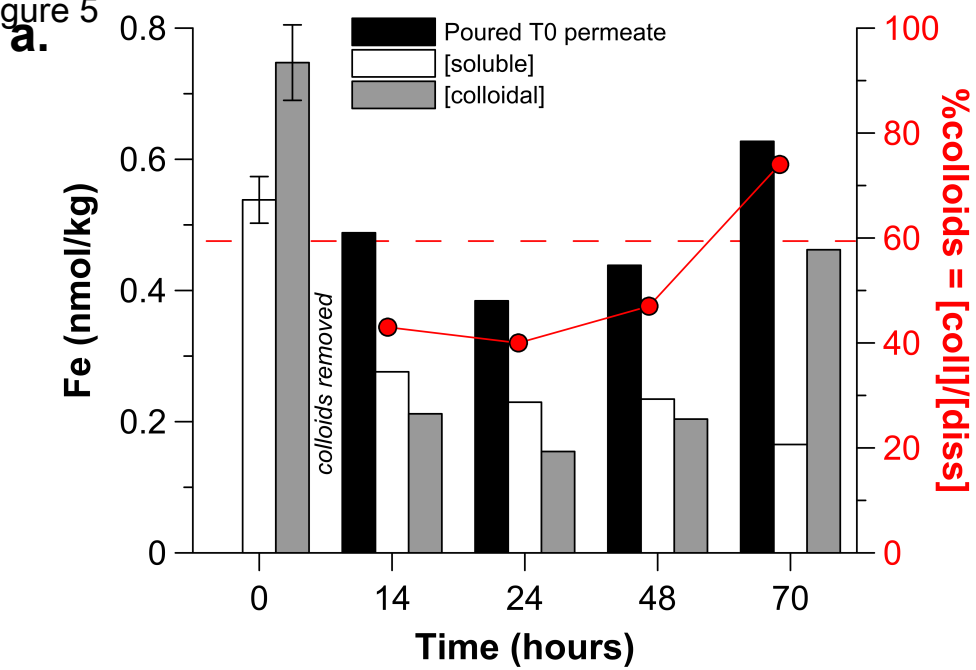

b.
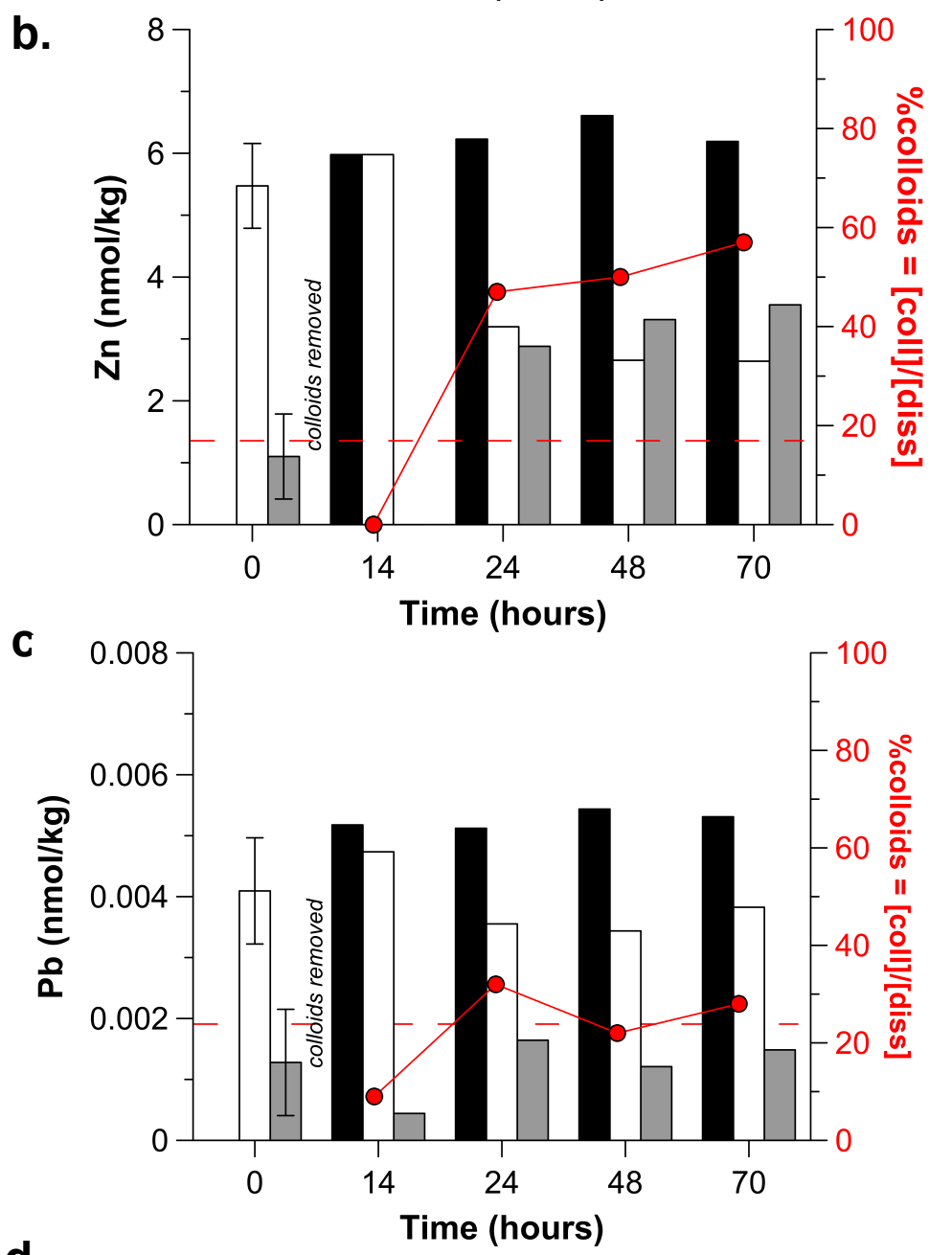

d.

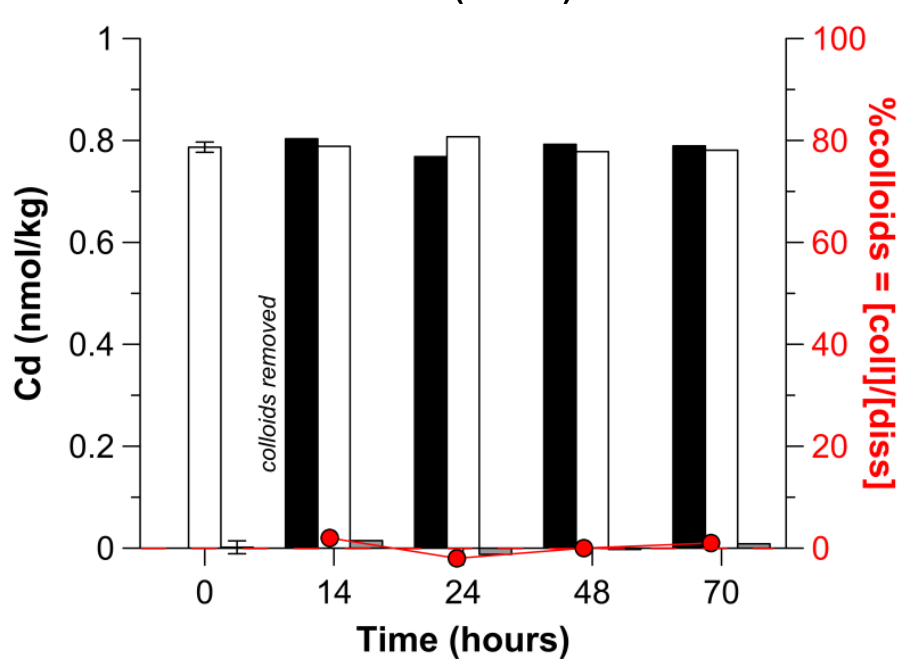

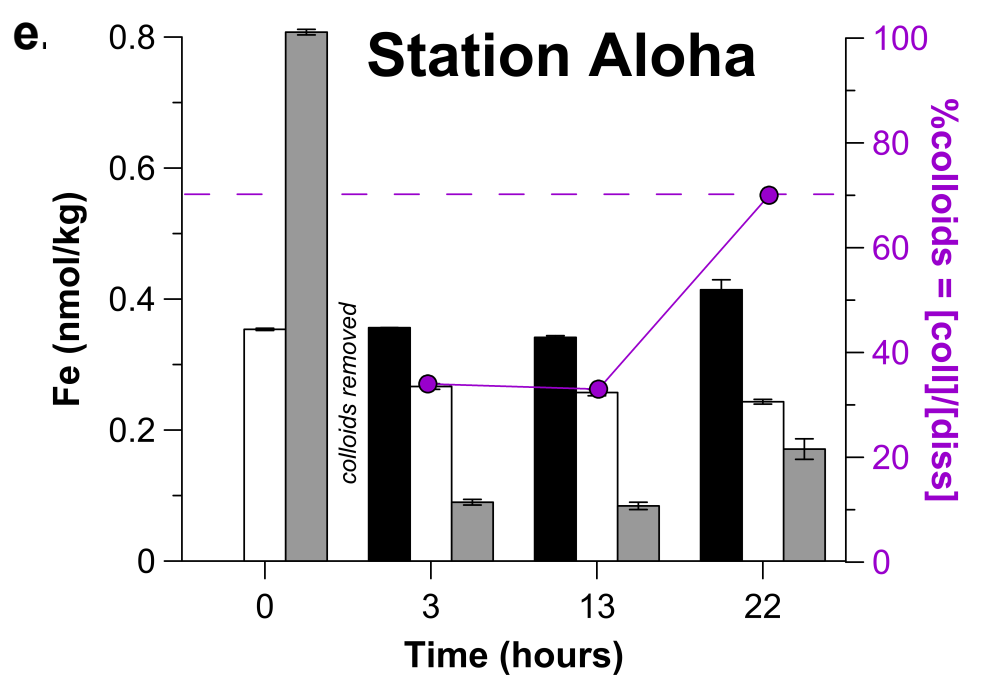

f.

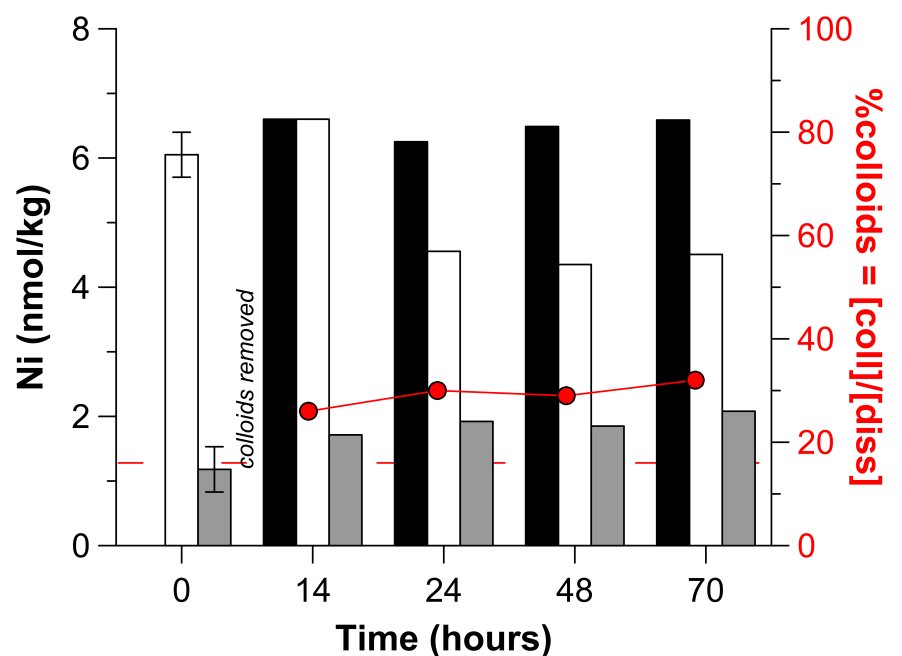

g.

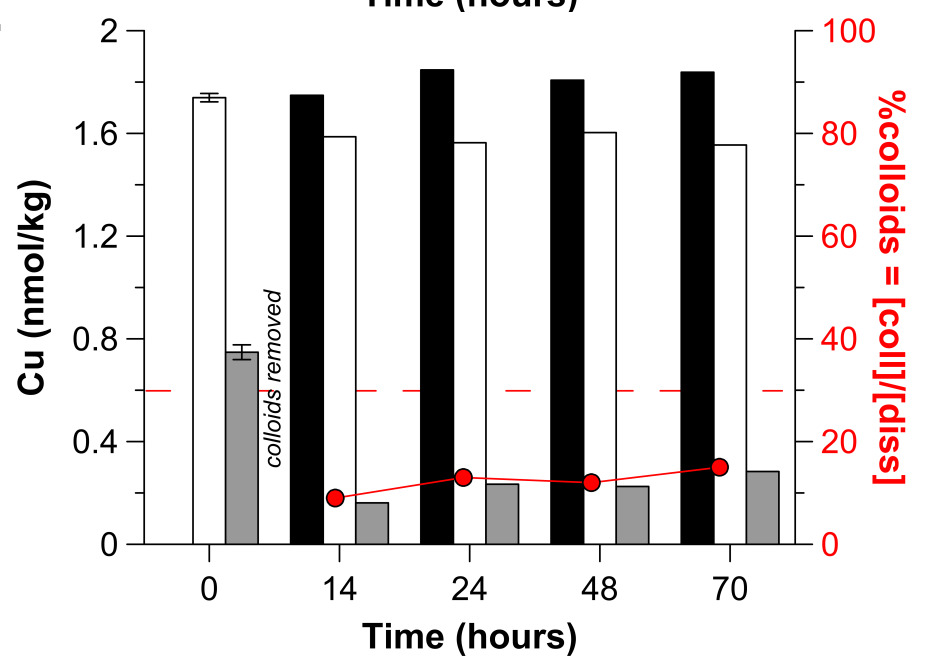

h.

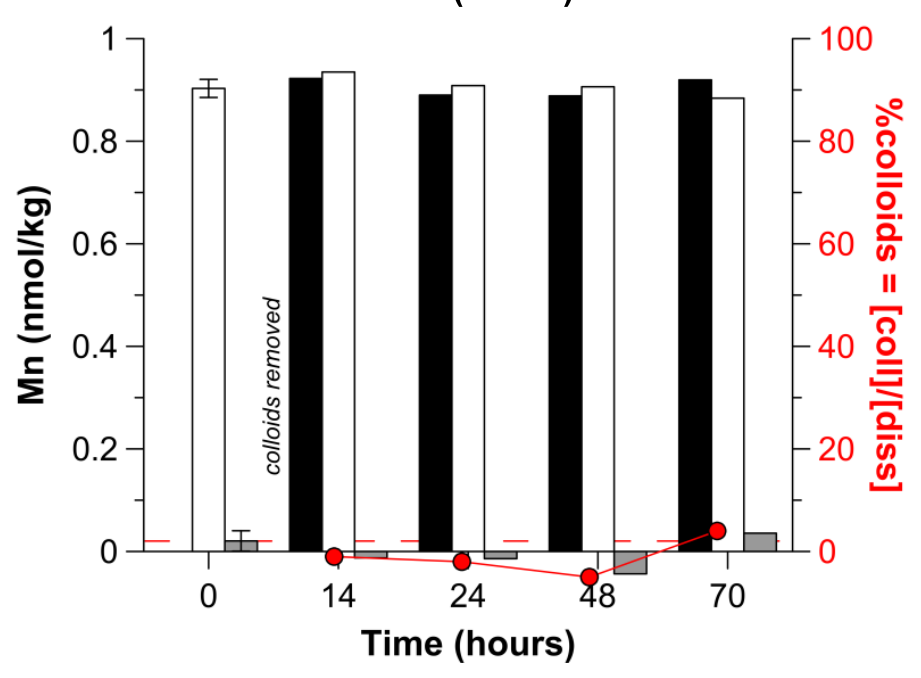


Figure 6
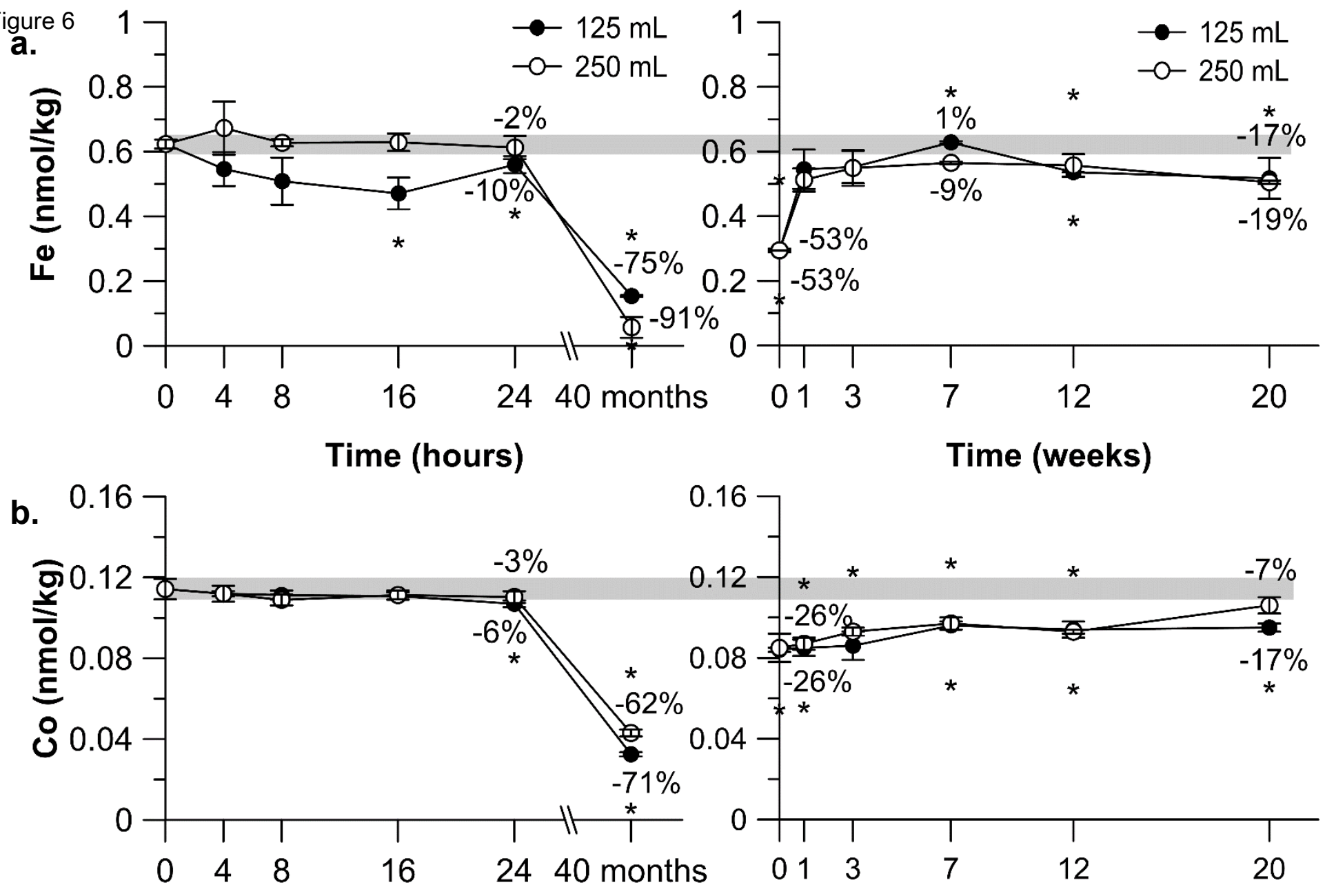

Time (hours)

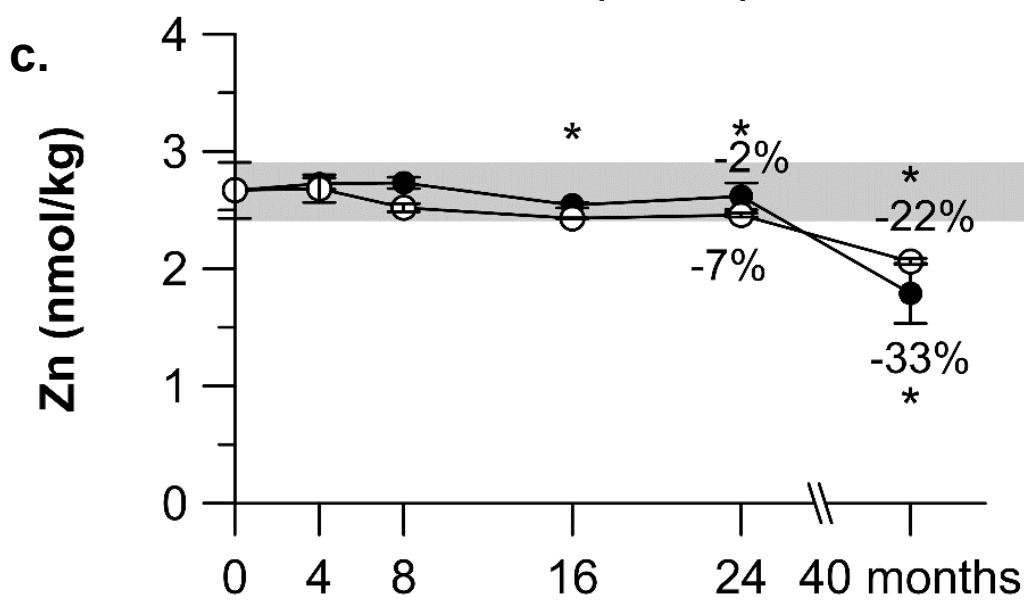

Time (hours)

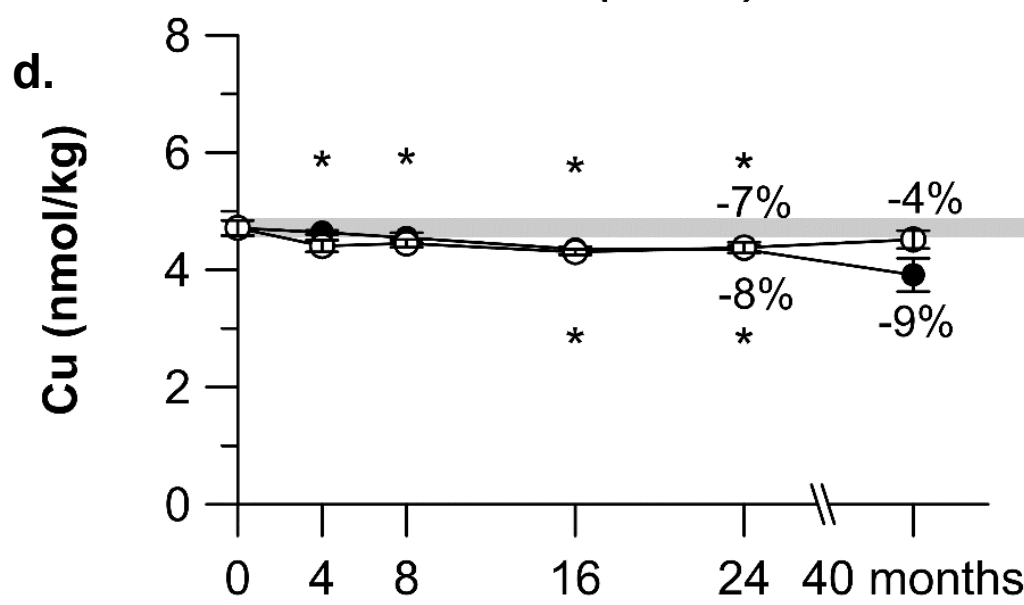

Time (hours)

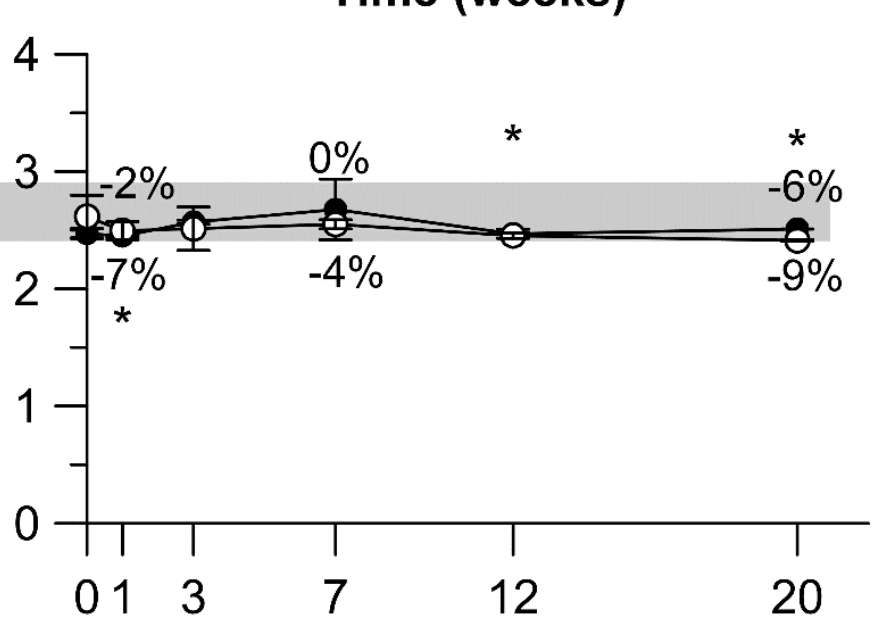

Time (weeks)

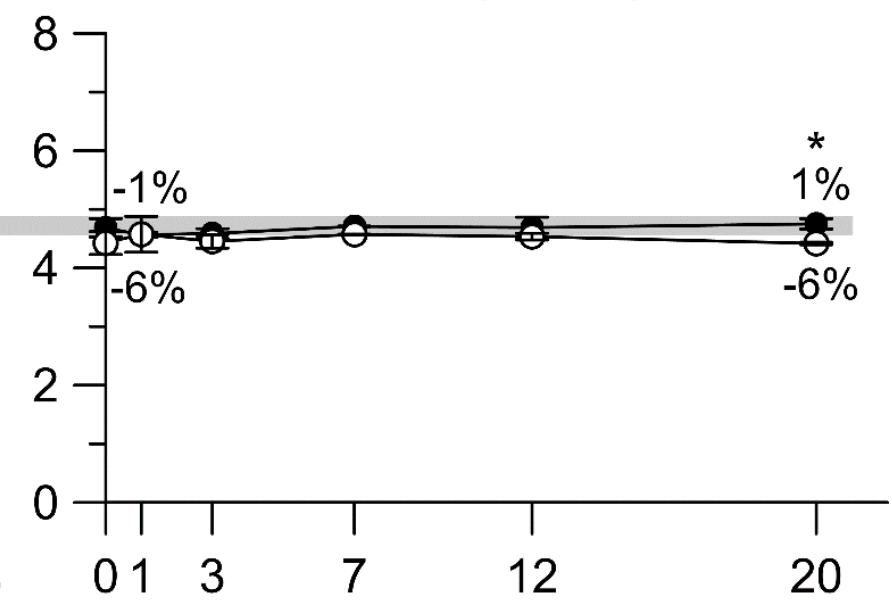

Time (weeks) 


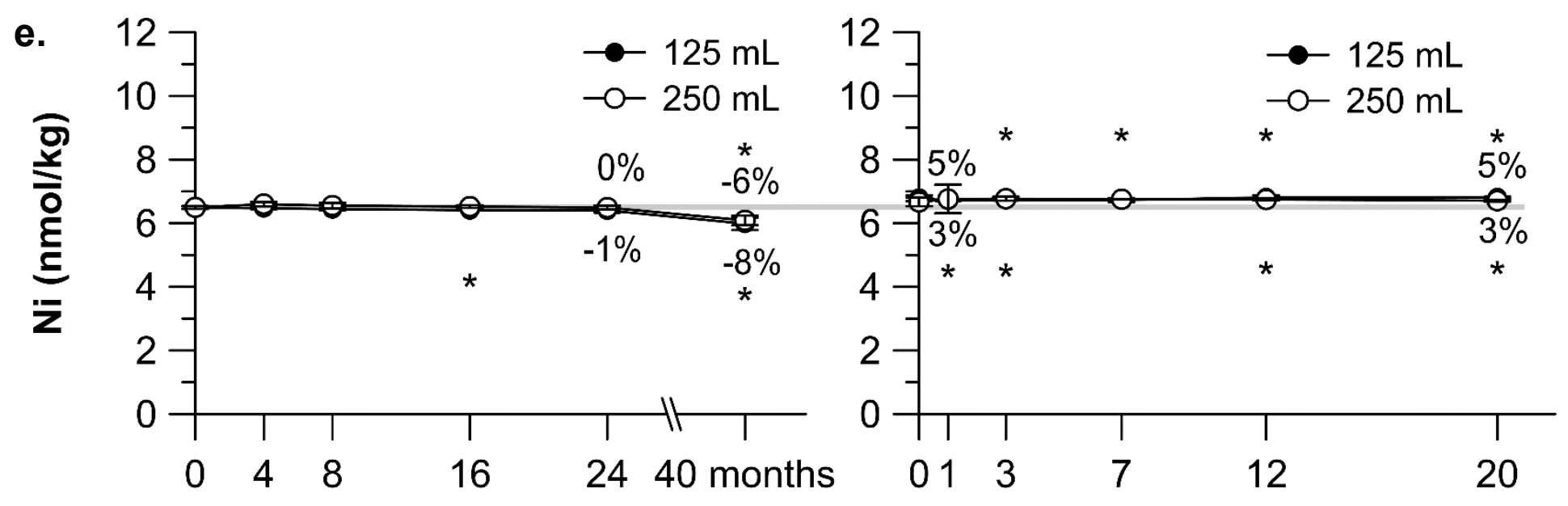

Time (hours)
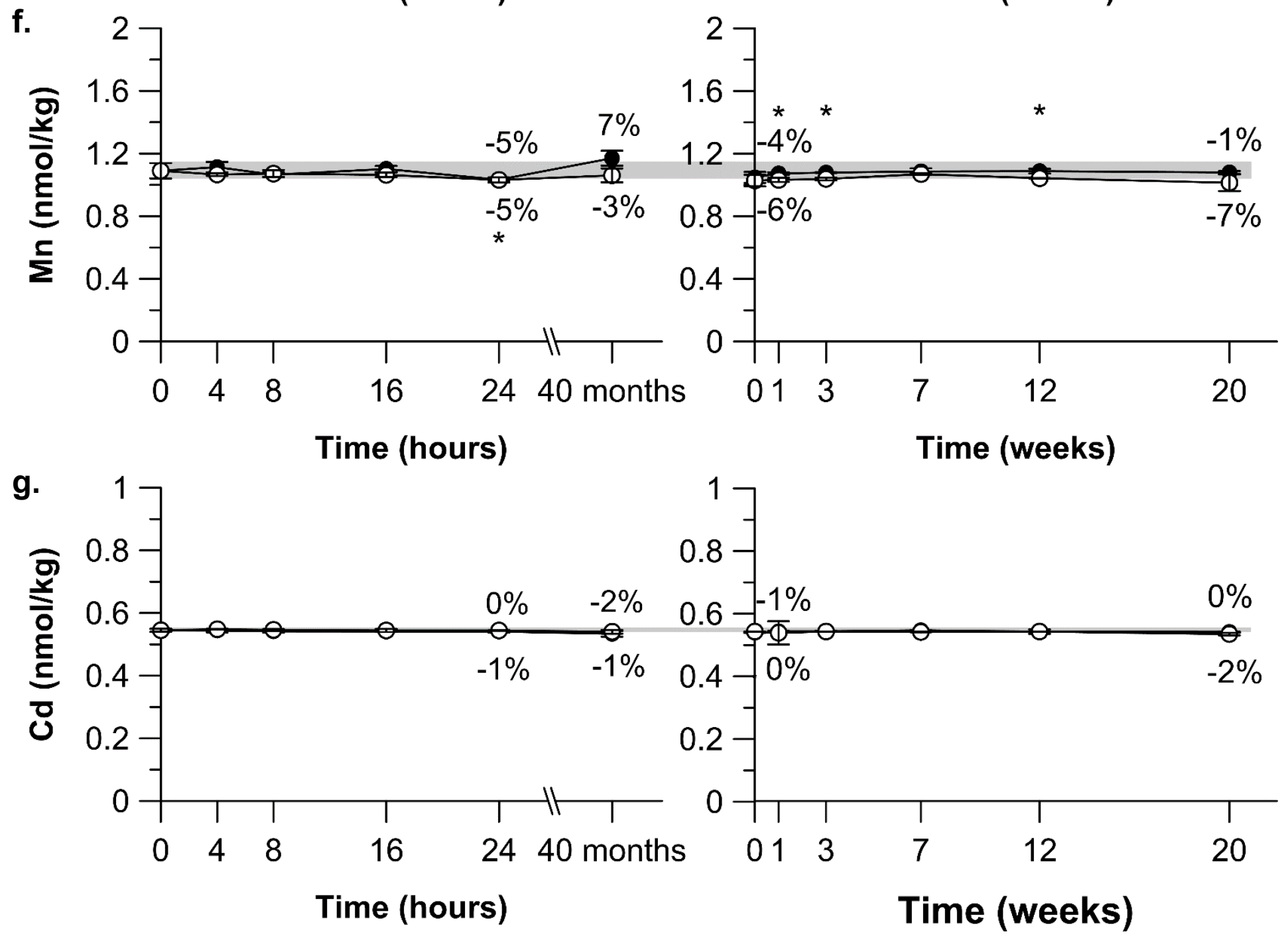